\title{
The nuclear GUCT domain-containing DEAD-box RNA helicases govern gametophytic and sporophytic development in Physcomitrium patens
}

\author{
Pierre-François Perroud ${ }^{1,7}$ (D) Viktor Demko ${ }^{2,3}$ - Ako Eugene Ako $^{4,8}$ (D) $\cdot$ Rajendra Khanal $^{4,9} \cdot$ Boris Bokor $^{2,5}$. \\ Andrej Pavlovič ${ }^{6}$ - Ján Jásik ${ }^{3}$. Wenche Johansen ${ }^{4}$ (i)
}

Received: 3 December 2020 / Accepted: 6 April 2021 / Published online: 22 April 2021

(c) The Author(s) 2021

\begin{abstract}
Key message In Physcomitrium patens, PpRH1/PpRH2 are GUCT-domain-containing DEAD-BOX RNA helicases localize to the nucleus. They are implicated in cell and tissue development in all stages of the moss life cycle.

Abstract The DEAD-box-containing RNA helicase family encompasses a large and functionally important group of enzymes involved in cellular processes committed to the metabolism of RNA, including its transcription, processing, transport, translation and decay. Studies indicate this protein family has implied roles in plant vegetative and reproductive developmental processes as well as response to environmental stresses such has cold and high salinity. We focus here on a small conserved sub-group of GUCT domain-containing RNA helicase in the moss Physcomitrium patens. Phylogenetic analysis shows that RNA helicases containing the GUCT domain form a distinct conserved clade across the green lineage. In this clade, the $P$. patens genome possesses two closely related paralogues RNA helicases predicted to be nuclear, $P p R H 1$ and $P p R H 2$. Using in-locus gene fluorescent tagging we show that $P p$ RH1 is localized to the nucleus in protonema. Analysis of $P p R H 1$ and $P p R H 2$ deletions, individually and together, indicates their potential roles in protonema, gametophore and sporophyte cellular and tissue development in P. patens. Additionally, the ultrastructural analysis of phyllid chloroplasts in $\Delta r h 2$ and $\Delta r h 1 / 2$ shows distinct starch granule accumulation under standard growth conditions associated with changes in photosynthetic activity parameters. We could not detect effects of either temperature or stress on protonema growth or $P p R H 1$ and $P p R H 2$ expression. Together, these results suggest that nuclear GUCT-containing RNA helicases play a role primarily in developmental processes directly or indirectly linked to photosynthesis activity in the moss P. patens.
\end{abstract}

Keywords RNA helicase $\cdot$ Development $\cdot$ Physcomitrium patens $\cdot$ Gametophyte $\cdot$ Sporophyte $\cdot$ Starch accumulation

Wenche Johansen

wenche.johansen@inn.no

$1 \quad$ Plant Cell Biology, Faculty of Biology, University of Marburg, Karl-von-Frisch Str. 8, 35043 Marburg, Germany

2 Department of Plant Physiology, Faculty of Natural Sciences, Comenius University in Bratislava, Ilkovicova 6, 84215 Bratislava, Slovakia

3 Plant Science and Biodiversity Center, Slovak Academy of Sciences, Dúbravská cesta 9, 84523 Bratislava, Slovakia

4 Department of Biotechnology, Inland Norway University of Applied Sciences, Holsetgata 31, 2318 Hamar, Norway

5 Comenius University in Bratislava Science Park, Ilkovicova 8, 84215 Bratislava, Slovakia
6 Department of Biophysics, Centre of the Region Haná for Biotechnological and Agricultural Research, Faculty of Science, Palacký University, Šlechtitelů 27, 78371 Olomouc, Czech Republic

7 Present Address: Institut Jean-Pierre Bourgin, INRAE, AgroParisTech, Université Paris-Saclay, 78000 Versailles, France

8 Present Address: School of Animal, Rural and Environmental Sciences, Nottingham Trent University, Brackenhurst Campus, Southwell NG25 0QF, Nottinghamshire, UK

9 Present Address: Department of Gastroenterology, Hepatology and Endocrinology, Hannover Medical School, Carl-Neuberg-Str. 1, 30625 Hannover, Germany 


\section{Introduction}

RNA helicases are important participants in essentially all biological processes related to RNA metabolism. These enzymes function as molecular motors to remodel RNA structures and ribonucleoprotein (RPN) complexes at the expense of adenosine triphosphate (ATP) hydrolysis in housekeeping pathways such as processing and editing of nuclear, chloroplast and mitochondrial transcripts, export and degradation of mRNA, translation initiation and ribosome biogenesis (Tanner and Linder 2001). Based on comparative structural and functional analyses, sequence similarities and conservation of specific motifs within the catalytic core of the enzyme, RNA helicases are currently classified into six superfamilies (SF1-SF6) (Singleton et al. 2007). SF2, the largest of the superfamilies, is further divided into several defined families, one of which is the DEAD-box family of RNA helicases (Fairman-Williams et al. 2010). The proteins in this family have received their name from the presence of a conserved stretch of amino acids D-E-A-D (Asp-Glu-Ala-Asp) in motif II. Motif II is one of 13 described conserved motifs $(\mathrm{Q}, \mathrm{I}, \mathrm{Ia}, \mathrm{Ib}, \mathrm{Ic}$, II, III, IV, IVa, V, Va, Vb and VI) defining the RNA helicases in this family (Fairman-Williams et al. 2010). The conserved motifs, required for ATP and RNA binding and for linking phosphoanhydride cleavage of ATP with helicase activity are distributed over two similar RecAlike domains, arranged in tandem and tethered by a flexible linker, constituting the basic catalytic helicase core (Tanner and Linder 2001). The eukaryotic eIF4A-family translation initiation factors, the smallest and founding members of DEAD-box RNA helicase family, consist of an isolated helicase core without $\mathrm{N}$ - and $\mathrm{C}$-terminal extensions/domains (Andreou and Klostermeier 2014), which are typically present in the majority of the DEAD-box proteins. These auxiliary extensions and domains mediate interactions with ATP, RNA and protein partners and are proposed to provide signals for subcellular localization, for modulating the activity of the helicase core and are thought to be critical for the physiological specificity of the helicase, thereby contributing to the functional diversity of this protein family (Fairman-Williams et al. 2010). The basic biochemical reaction of DEAD-box proteins, RNA unwinding coupled to ATPase activity, is just one of several activities identified for these enzymes; some enzymes display strand annealing activity, promoting duplex formation, others are involved in protein displacement to remodel RPN complexes or function as assembly platforms to increase their size (Putnam and Jankowsky 2013).

The RNA helicase gene families in plants are larger and more diverse compared to those in other organisms
(Linder and Owttrim 2009). The analysis of the complete genomes from Arabidopsis thaliana, Oryza sativa, Glycine max and Zea mays revealed 161, 149, 136 and 213 unique genes, respectively, encoding putative RNA helicases in these organisms (Xu et al. 2013). Of these, 50, 51, 57 and 87 proteins were classified as DEAD-box RNA helicases, respectively. Experimental evidence for biochemical activities of these proteins is limited, but available data shows that plant DEAD-box RNA helicases have important functions in plant growth and development, and in various stress responses (Linder and Owttrim 2009). eIF4A proteins are among the more thoroughly characterized DEAD-box proteins. Plants (and mammalians) express three eIF4A proteins, eIF4A1, eIF4A2 and eIF4A3, exhibiting RNA-stimulated ATPase activity and RNA unwinding activity (Rogers et al. 1999), functioning in translation initiation (eIF4A1 and eIF4A2) and in the assembly of the exon junction complex (eIF4A3) (reviewed by Andreou and Klostermeier 2014). Available data from several plant species clearly indicate that elF4A proteins are essential for normal plant growth and development, possibly by regulating protein translation during the cell cycle (Hutchins et al. 2004; Bush et al. 2009, 2016). In A. thaliana, both eIF4A1 (AT3G13920) and eIF4A2 (AT1G54270) are expressed in actively dividing cells, and an elF4A1 mutant, producing a putative truncated elF4A 1 version, shows slow growth and reduced lateral root formation, delayed flowering and abnormal ovule development (Bush et al. 2015). In the early land plant Physcomitrium patens, deletion of a conserved region of Pp3c6_1080V3.1, encoding the helicase core motifs of eIF4A1/eIF4A2, produce mutant plants with slowed protonemata growth and dwarfed leafy gametophores with reduced stems and internodes, suggesting a role for eIF4A1/eIF4A2 in cell division and/or elongation (Tyagi et al. 2020). In the same study, a function for eIF4A1/eIF4A2 in stress response was identified by the observation of a strong and rapid accumulation of Pp3c6_1080V3.1 transcripts under increased salinity. The Pp3c6_1080V3.1 knock-out mutant exhibits a slow-recovery phenotype after salt stress treatment, also suggesting a role for eIF4A1/eIF4A2 in stress management in $P$. patens. Several other DEAD-box proteins have been shown to be involved in various stress responses in plants. The DEAD-box protein TOGR1 (Thermotolerant Growth Required1; LOC_Os03g46610) in O. sativa maintains normal rRNA homeostasis at high temperature, the helicase activity directly promoted by an increase in temperature (Wang et al. 2016). Conversely, DEAD-box RNA helicase 42 (OsRH42, LOC_Os08g06344) in O. sativa was shown to be necessary for effective splicing of pre-mRNA during mRNA maturation at low temperatures ( $\mathrm{Lu}$ et al. 2020). In two comprehensive expression profiling studies in tomato, organ- and/or tissue-specific expression patterns 
of DEAD-box RNA helicases were observed in relation to various abiotic (Cai et al. 2018) and biotic (Pandey et al. 2019) stress conditions, thus providing evidence for RNA helicases performing diverse roles in cellular stress responses and during plant growth and development.

DEAD-box RNA helicases function in different compartments of the cell, including the cytosol, nucleus, chloroplast and mitochondria. A. thaliana DEAD-box RNA helicase 7 (AtRH7/PRH75; AT5G62190) is localized to the nucleolus (Lorković et al. 1997), harbours dsRNA unwinding activity (Nayak et al. 2013) and participates in pre-rRNA processing and possibly ribosome assembly (Huang et al. 2016). AtRH7 is ubiquitously expressed in both vegetative and reproductive tissue and promoter-GUS constructs indicated that this gene is transcriptionally active mainly in regions undergoing cell division (Huang et al. 2016). Disruption of the AtRH7 gene caused severe developmental defects including abnormal embryo and seedling development, in addition to delayed seed germination showing the importance of this protein in plant development (Huang et al. 2016). AtRH7 is also implicated in cold tolerance/acclimation as AtRH7 transcription is slightly upregulated in cold-treated seedlings; transcript levels are unaffected by osmotic, salt, drought and heat stresses. AtRH3 (AT5G26742), DEAD-box RNA helicase 3 from $A$. thaliana, is localized to the chloroplasts (Peltier et al. 2006). The accumulation of AtRH3 and the maize orthologue (ZmRH3A) are strongly controlled during plant development, the RH3 proteins functioning in splicing of group II introns, maturation of rRNA and possible also in ribosome biogenesis (Asakura et al. 2012). The AtRH3 gene is essential in A. thaliana as null mutants are embryo lethal. AtRH3 and AtRH7 both contain a C-terminal GUCT (NUC152) domain for which no function has been described. A GUCT domain has also been identified in human RNA DEAD-box protein 21 (DDX50; RHII/Guß), a multifunctional enzyme with RNA-unwinding and RNA-folding activities (Valdez et al. 1997). Bioinformatic analyses of the GUCT domain have shown the presence of the RNA recognition motif (RRM) fold in RH-II/Gu $\beta$, a fold typically found in RNAinteracting proteins, however without the essential amino acid residues important for RNA recognition, suggesting that the GUCT domain of RH-II/Gu $\beta$ is unlikely to interact with RNA (Ohnishi et al. 2009). Mutagenesis studies also showed that the GUCT domain is not essential for RH-II/ $\mathrm{Gu} \beta$ helicase or foldase activity (Valdez et al. 1997; Valdez 2000). Thus, the function of the GUCT domain in DEADbox RNA helicases still remains elusive.

With diverse domain composition and sub-cellular localization, DEAD-box RNA helicases have been implicated in a broad array of developmental and stress-related functions. Our research aims to elucidate the biological role of two newly identified GUCT-domain containing DEADbox RNA helicases (PpRH1; Pp3c20_20710 and PpRH2;
Pp3c10_20840) in the moss $P$. patens. Using primarily a reverse genetic approach, we focus on phenotypic characterization to pinpoint their function in both developmental processes and stress responses. In the present study, we show that the GUCT-domain containing DEAD-box RNA helicases are present in the green lineage since its inception. We demonstrate $P p$ RH1 nuclear localization in the moss $P$. patens. Through the individual deletion of $\mathrm{PpRH} 1$ and $\mathrm{PpRH} 2$ and their deletion in a double mutant, we show that, together, they are necessary for normal morphological vegetative development and necessary for sporophytic development. In contrast to other plant DEAD-box RNA helicases, GUCTdomain-containing DEAD-box RNA helicases apparently do not affect moss response to environmental stresses but PpRHI and PpRH2 mutants display both aberrant photosynthetic activity and starch accumulation.

\section{Results}

\section{PpRNA helicase 1 and 2 belong to the DEAD-box RNA helicase family}

The P. patens RNA helicase 1 (Pp3c20_20710) and RNA helicase 2 (Pp3c10_20840), hereafter referred to as $P p$ RH1 and $P p \mathrm{RH} 2$, respectively, are $87 \%$ identical at the amino acid level and are encoded by 7-exon-genes on chromosomes 20 and 10 , respectively. While the exon structure of the corresponding genes is highly conserved, their coding sequences being $79 \%$ identical, the sizes of the introns vary between the two, particularly intron 1 of $P p R H 2$, which is $46 \%$ larger than that of PpRHI (Supplementary Table S1). The two proteins contain putative nuclear localization signals (NLS), a conserved helicase core region with the DEAD-box motif and consisting of the Pfam domains DEAD (Pfam code: PF00270) and helicase_c (Pfam code: PF00271), in addition to a C-terminal GUCT domain (Pfam code: PF08152) (Fig. 1a). The 13 described signature motifs characteristic for the helicase core of SF2 proteins, Q, I, Ia, Ib, Ic, II, III, IV, IVa, V, Va, Vb and VI (Fairman-Williams et al. 2010) are present in both $P p$ RH1 and $P p$ RH2, and are $100 \%$ conserved between the two proteins (Fig. 1a). Of the three domains identified, GUCT is the less conserved domain of $P p$ RH1 and $P p$ RH2 with a sequence identity of $86 \%$. GUCT domains are currently identified in approximately 1000 different Pfam sequences, arranged in 30 different protein architectures, mainly in combination with the DEAD and/ or helicase_c domains of eukaryotic proteins. Interestingly, the GUCT domain has so far not been identified in archea, viruses and viroids, and only in a limited number (23) of bacterial species exclusively belonging to the DeinococcusThermus phylum, a group of extremophiles known to be 

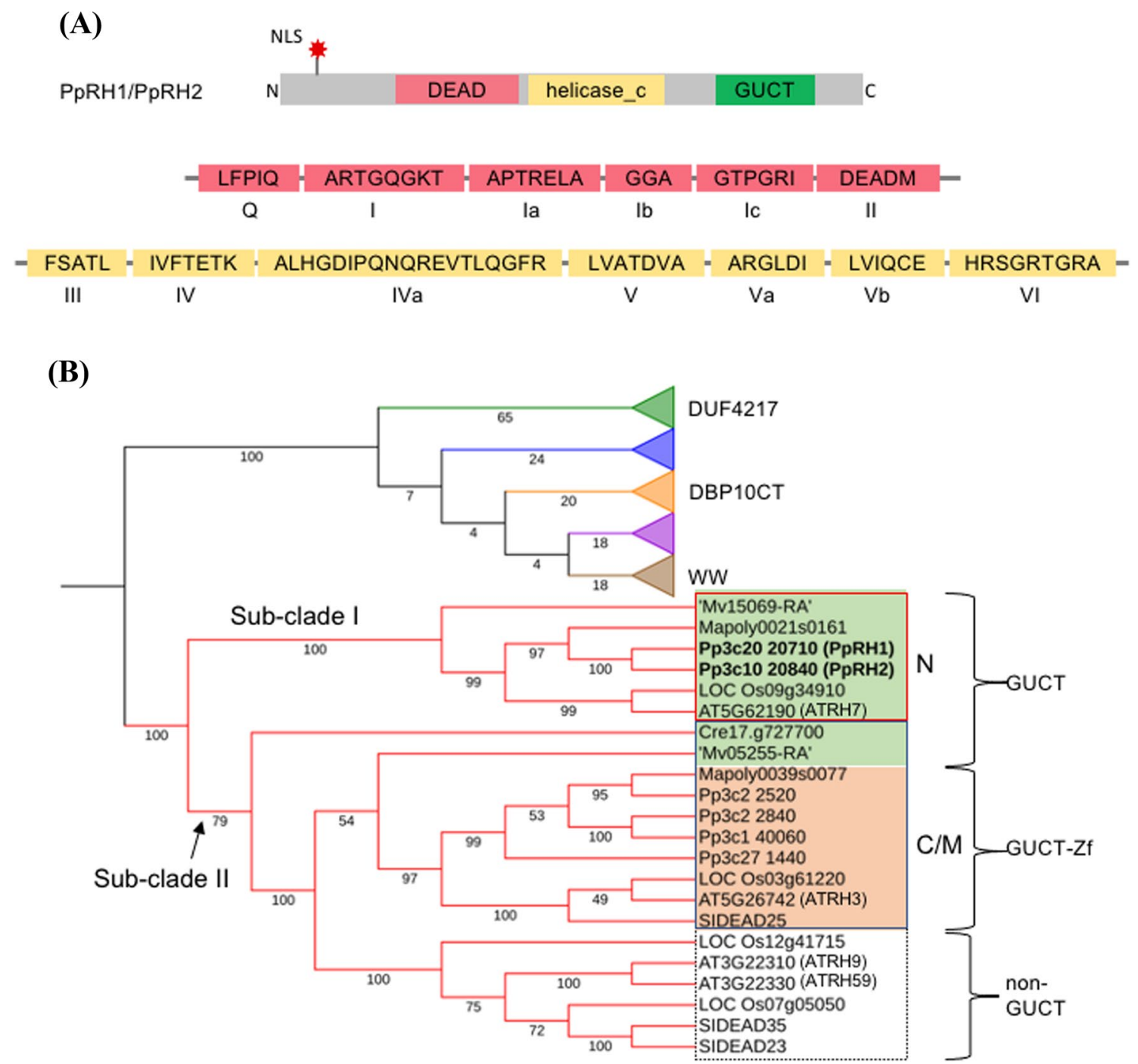

Fig. 1 Structure and phylogenetic analysis of $P p$ RH1 and $P p$ RH2. a Schematic representation of the identical domain structure (DEAD (red), helicase_c (yellow) and GUCT (green), core motifs (Q, I, Ia, Ib, Ic, II, III, IV, IVa, V, Va, Vb and VI) and the predicted nuclear localization signal (NLS) (red star) in proteins $P p$ RH1 and $P p$ RH2. The amino acid sequence of the motifs is highlighted in the red and yellow boxes and are identical between the two proteins. Figure not drawn to scale. b Partly collapsed phylogenetic tree of the DEAD-box RNA helicase family members from A. thaliana, S. lycopersicum, $O$. sativa, $P$. patens, $M$. polymorpha, $M$. viride and $C$. reinhardtii. All the GUCT-containing helicases are clustered into one major clade, sepa-

highly resistant to environmental hazards, including radiation and high/low temperatures (Ho et al. 2016).

Sequence similarity searches (pBLAST) using PpRH1 as query resulted in the identification of 47 P. patens, 28 Marchantia polymorpha, 35 Mesostigma viride and 37 Chlamydomonas reinhardtii RNA helicases containing the DEAD-box motif. The domain structure and sizes of these proteins, in addition to their homologues in Solanum lycopersicum (Pandey et al. 2019), O. sativa and A. thaliana rated from the majority of the remainder of the RNA helicases which are further clustered into 5 subclades. The helicases containing the DUF4217, DBP10CT or WW domains are each clustered separately into individual sub-clades as shown in more detail in Supplementary Fig. S1. The helicases containing GUCT (green box) or GUCT-Zf_ CCHC (orange box) are clustered into two sub-clades, I (red frame) and II (blue frame), and are predicted and/or annotated to be localized to the nucleus $(\mathrm{N})$ or the chloroplast/mitochondria $(\mathrm{C} / \mathrm{M})$, respectively. The non-GUCT containing RNA helicases are shown in in the white box

(Xu et al. 2013) can be found in Supplementary Table S2. Structural analysis of the selected RNA helicases from these organisms, representing major Viridiplantae groups, revealed that only a restricted number of additional domains, including WW (PF00397), DUF4217 (PF13959), DBP10CT (PF08147), GUCT and Zf_CCHC (PF00098), are found in combination and in an identical arrangement to the helicase core. With the exception of zinc knuckle (Zf_CCHC) domain, all other domains (WW, DUF4217, DBP10CT, 
GUCT) were found across all analyzed species, suggesting that the different DEAD-box RNA helicase structures were established already in the common ancestor of Chlorophyta and Streptophyta. To further investigate the evolutionary relationship of the sampled DEAD-box RNA helicase, a phylogenetic analysis was performed using the core helicase region of the proteins listed in Supplementary Table S2. In this analysis, we excluded sequences containing large insertions between the two helicase core domains (DEAD and helicase_c), a specific architecture we exclusively detected in the algae, possibly representing an evolutionary group lost by land plants. Similar to previous studies (Pandey et al. 2019), the phylogenetic analysis revealed that the DEADbox RNA helicases cluster into six clades (Fig. $1 \mathrm{~b}$ and Supplementary Fig. S1). PpRH1 and PpRH2 form one major phylogenetic group together with all RNA helicases containing the GUCT domain, distinctly separated from the vast majority of the other DEAD-box RNA helicases, which are further clustered into five sub-clades. RNA helicases containing the WW, DUF4217 or DBP10CT domains are each clustered separately into one sub-clade (Fig. 1b and Supplementary Fig. S1). The clade containing the RNA helicases harboring the GUCT domain can be further divided into two sub-clades (Fig. 1b); one sub-clade (I) consists of proteins exclusively with the DEAD-helicase_C-GUCT domain architecture and the second sub-clade (II) contains RNA helicases with either the helicase core only, the helicase core plus GUCT or the helicase core with the GUCT and Zf_CCHC domains arranged in tandem. Importantly, all RNA helicases in sub-clade I are predicted to be nuclear localized, as opposed to the GUCT-Zf_CCHC-containing RNA helicases in sub-clade II which are either predicted or annotated as chloroplastic or mitochondrial proteins (Supplementary Table S2). In agreement with the prediction of a nuclear localization signal, the $A$. thaliana DEAD-box ATP-dependent RNA helicase 7 (also known as AtRH7; AT5G62190) was previously shown experimentally to be localized to the nucleus (Lorković et al. 1997). This evidence supports our phylogenetic analysis suggesting that GUCTcontaining RNA helicases are clearly organelle associated proteins, destined either for the nucleus or the mitochondria/ chloroplast. Our results further suggest that the $\mathrm{Zf}$ _CCHC domain of the GUCT-containing RNA helicases was established in land plants after the split of the charophyte algae.

\section{PpRH1 and PpRH2 are ubiquitously expressed in $P$. patens tissues}

We performed a developmental transcript accumulation profiling using the RNA-seq Developmental stages gmv3.3 data set and the PEATmoss tool (Fernandez-Pozo et al. 2020). Both $P p R H 1$ and $P p R H 2$ appear to be ubiquitously expressed throughout the P. patens life cycle (Fig. 2a).
However, $P p R H I$ is systematically expressed 2 to 10 times higher than $P p R H 2$ across different tissues. This expression pattern was independently observed by the Physcomitrella eFP browser tool (Ortiz-Ramírez et al. 2016) (Supplementary Fig. S2). Subsequently quantitative reverse-transcription polymerase chain reaction (qRT-PCR) performed on protonema after 6 days of growth and protonema with gametophores after 14 days of growth confirmed the clear differential expression between PpRH1 and PpRH2 (Fig. 2b).

According to the information extracted from the PEATmoss tool, variations of environmental conditions such as light, temperature or the hormone abscisic acid (ABA) do not appear to have an effect on the transcription of $P p R H 1$ and $P p R H 2$ (data not shown). Similarly, other studies did not detect any variation in transcript accumulation from these two genes in response to either mild or high heat (Elzanati et al. 2020) or cold treatment (Khraiwesh et al. 2015).

\section{PpRH1 is localized in the nucleus of growing protonema}

To evaluate the cellular localization of $P p \mathrm{RH} 1$, we generated the $r h 1-3 x g f p$ strain containing a GFP triplicate C-terminal tag (Supplementary Result S1 and Supplementary Fig. S3). rhl-3xgfp is morphologically undistinguishable from wildtype (WT) during the gametophytic and sporophytic phases of its life cycle. This strain displays a low GFP signal only detectable using a time-gating approach to subtract non-specific background fluorescence (Perroud et al. 2020). Rhll$3 x g f p$ shows a nuclear-specific signal in protonemal cells of blended cultures of the primary transformant (Fig. 3a-c and Supplementary Fig. S4 for comparison with untransformed control) as well as in young sporeling (Fig. 3d-f) produced by selfed sporophytes. The fluorescent signal is strongest in cells near the tip and nuclear signal intensity is reducing along the filament main branch. In secondary branching filaments, this pattern is repeated. No fluorescent signal, nuclear or otherwise, was detected in other vegetative, sexual or sporophytic tissues.

\section{The lack of PpRH1 and PpRH2 in single and double mutants differently affects gametophyte growth and development.}

To study the function of $P p \mathrm{RH} 1$ and $P p \mathrm{RH} 2$, we generated the single gene knockout lines $\Delta r h 1$ and $\Delta r h 2$, respectively. In addition, we generated the double knockout line $\Delta r h 1 / 2$, in which both PpRH1 and PpRH2 were deleted (for information regarding the mutants we refer to Supplementary Result S1 and Supplementary Fig. S5). We first assessed the role of $P p \mathrm{RH} 1$ and $P p \mathrm{RH} 2$ during gametophytic development of $P$. patens by analyzing $\Delta r h 1, \Delta r h 2$ and $\Delta r h 1 / 2$ alongside with wild-type strain (WT) grown 
Fig. $2 P p R H 1$ and $P p R H 2$ transcript accumulation in Physcomitrium patens wildtype and mutant plants. a Bar plots showing the normalised expression levels (in RPKM) of $P p R H 1$ and $P p R H 2$ at different developmental stages of the WT P. patens life cycle. Data extracted from the RNA-seq Developmental stages gmv3.3 dataset of the PEATmoss online tool and from the Meyberg et al. (2020) RNA-seq experiment for the antheridia bundles stage. b Quantitative reverse-transcription PCR analysis representing fold change in $P p R H I$ and $P p R H 2$ gene expression in wildtype and mutant plants $(\Delta r h l$ and $\Delta r h 2)$ grown for 6 and 14 days relative to the $P p R H 2$ level in 6-day-old wild-type plants, which was set to 1. Error bars represent the standard error (se) of two biological replicates. nd: no detectable transcripts; d: days
(A)
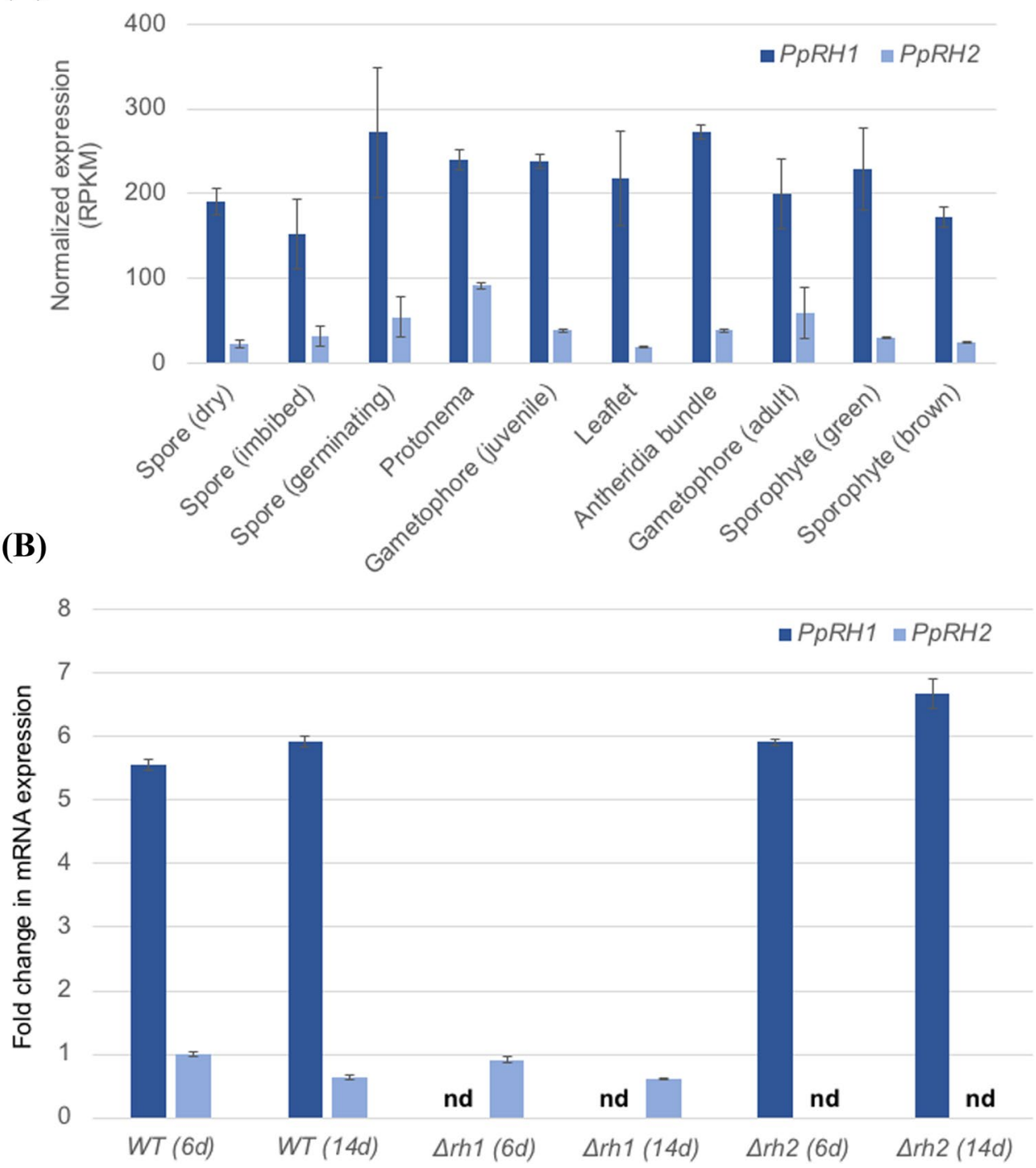

under standard conditions (Fig. 4). We did not observe any phenotypic differences between WT and $\Delta r h l$ at any gametophytic growth stage investigated. The $\Delta r h l$ showed wild-type spread of protonemata and wild-type morphology of leafy gametophores (Fig. 4a). The growth of sidebranches that extend from primary filaments was also similar between WT and $\Delta r h 1$ (Fig. 4b). Quantification of plants spreading, gametophore length and side-branch extension confirmed no significant differences between WT and $\Delta r h l$ (Fig. 4c).

In contrast to $\Delta r h 1$, the phenotypes of $\Delta r h 2$ and $\Delta r h l / 2$ were strikingly different. The $\Delta r h 2$ mutant showed slightly reduced spread of protonemata, however the cultures appeared bushier (Fig. 4a). Closer examination of isolated filaments revealed that increased density of $\Delta r h 2$ plants was caused by accelerated growth of side-branches formed on primary filaments (Fig. 4b). Quantitative data showed about three-times longer side branches in $\Delta r h 2$ compared to WT and $\Delta r h l$ (Fig. 4c). Gametophores of $\Delta r h 2$ mutant were longer compared to WT (Fig. 4a, c), and appeared narrower, resembling signs of mild etiolation, despite growing under standard conditions. This feature of gametophore growth was clearly manifested after long-term cultivation under reduced light (Supplementary Fig. S6).

The deletion of both PpRHI and PpRH2 genes in the $\Delta r h 1 / 2$ mutant caused a more severe phenotype in protonemata and gametophores. Protonema spreading was strongly reduced resulting in small dense plants (Fig. 4a). Closer examination of isolated filaments revealed an abnormal branching pattern with predominance of chloronemal cells (Fig. 4b). Although with approximately corresponding phyllid numbers, one-month old gametophores of $\Delta r h 1 / 2$ were dramatically stunted in comparison to WT and the single mutants (Fig. 4a, c). 

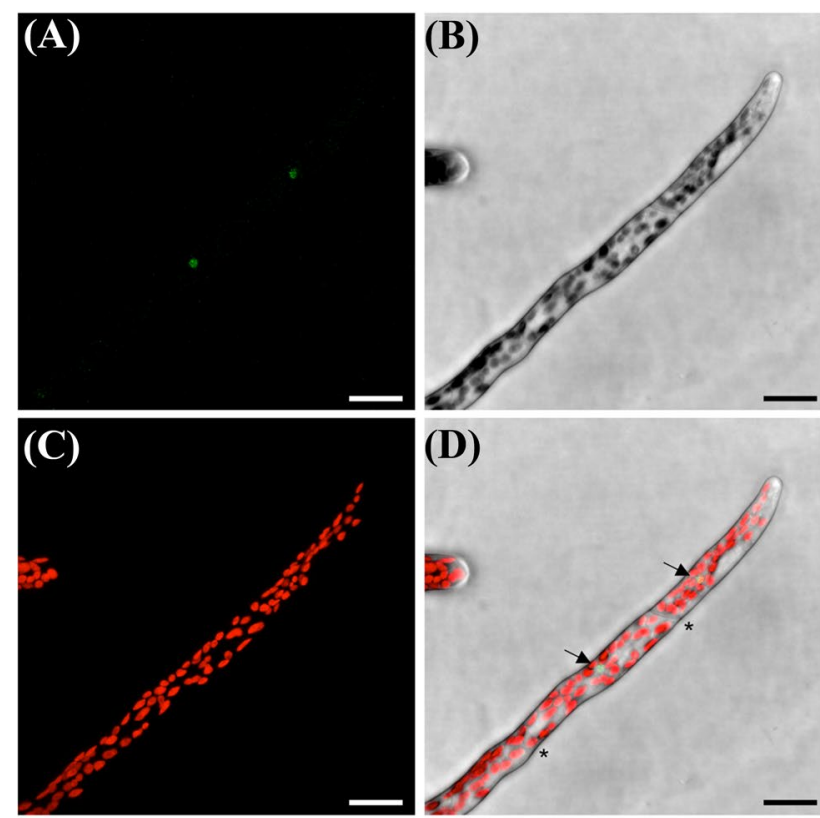

(D)
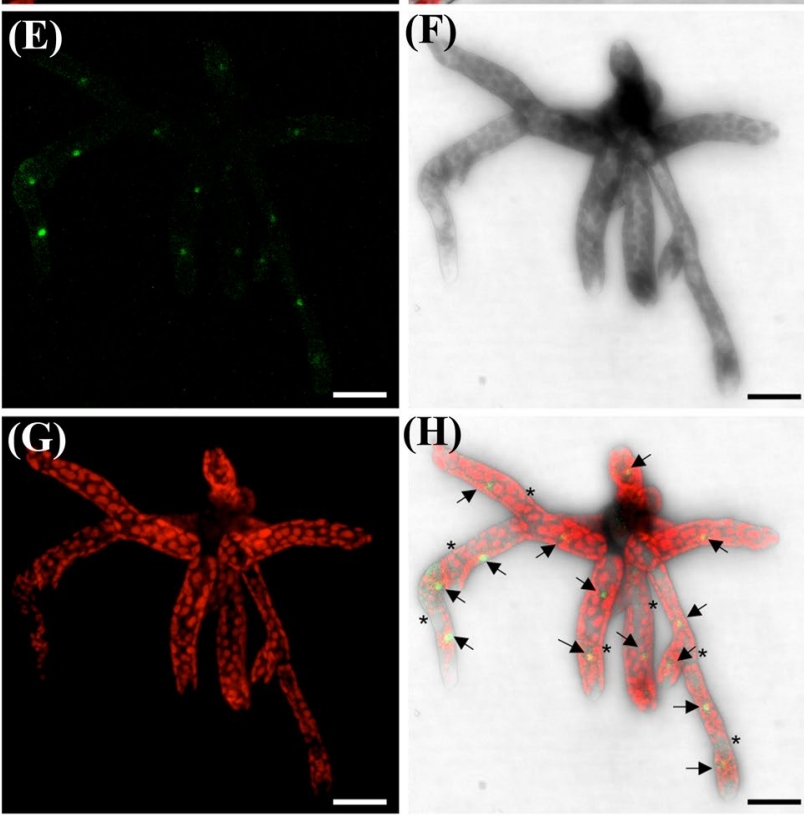

(H)

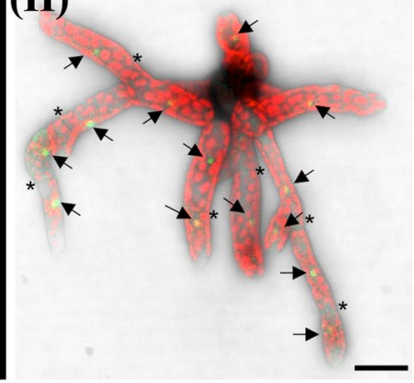

Fig. 3 PpRH1-3xGFP localizes in the nucleus of Physcomitrium patens protonemal cells. a-d Tip cell of filament propagated vegetatively. Bar: $25 \mu \mathrm{m}$. e-h Five-day-old sporeling. PpRH1-3xGFP specific fluorescent signal confocal stack. $\mathbf{b}$ and $\mathbf{f}$ Average projection of confocal stack of transmitted light signal. $\mathbf{c}$ and $\mathbf{g}$ Maximum projection of chlorophyll auto-fluorescence signal confocal stack. $\mathbf{d}$ and $\mathbf{h}$ Merged a-c and e-f images, respectively. Arrows point to nuclei. * denotes the filament intercalary cell walls. Bar: $25 \mu \mathrm{m}$

\section{Stress conditions do not alter developmental differences between mutants}

In order to examine whether $P p$ RH1 and $P p$ RH2 contribute to developmental plasticity in response to stress, we cultivated both single mutants and the double mutant for 2 weeks under low light, high light and salt stress. As shown in Supplementary Figs. S7, S8 and S9, both single mutants and double mutant respond to the stress factors similarly to WT while maintaining their characteristic phenotypic features as described above. For details, please see Supplementary Result S1.

To assess steady-state levels of $P p R H 1$ and $P p R H 2$ transcripts in response to stress treatments, we treated 2-weekold cultures grown under standard conditions with cold $\left(10^{\circ} \mathrm{C}\right)$ and abscisic acid (ABA $\left.10 \mu \mathrm{M}\right)$, respectively, for $24 \mathrm{~h}$. The ABA treatment caused mild increase of PpRHI expression both in WT and the $\Delta r h 2$ mutant, whereas $P p R H 2$ expression, whose expression was concistently lower than that of PpRH1, was not significantly altered in WT nor in $\Delta r h l$ compared to the corresponding un-treated plants (Supplementary Fig. S10). Cold treatment did not affect PpRHI expression in WT plants and we measured only a mild transcript increase for this gene in $\Delta r h 2$. No major effect of cold was detected in the expression of PpRH2 in WT and the $\Delta r h 1$ mutant (Supplementary Fig. S10).

\section{Photosynthetic performance is moderately affected in $\Delta r h 2$ and $\Delta r h 1 / 2$ mutants and reflects developmental alterations}

Morphological alterations in $\mathrm{PpRH} 1$ and $\mathrm{PpRH} 2$ mutants, and especially etiolation-reminiscent phenotype of gametophores in $\Delta r h 2$, led us to evaluate their photosynthetic performance under standard conditions and when subjected to stress (Fig. 5a).

Maximum quantum yield of photosystem II $\left(\mathrm{F}_{\mathrm{v}} / \mathrm{F}_{\mathrm{m}}\right)$ reflects potential quantum efficiency of PSII and is a sensitive indicator of plant photosynthetic performance with optimal values of around 0.83 for most plant species (Maxwell and Johnson 2000). The Bryophytes have lower $\mathrm{F}_{\mathrm{v}} / \mathrm{F}_{\mathrm{m}}$ values which do not exceed 0.8 indicating the presence of more intensive photoinhibition than in vascular plants at moderate light intensities (Hájek et al. 2009). This was also the case in our study, the highest $F_{v} / F_{m}$ values were found under low light condition and the lowest under high-light condition, indicating mild photoinhibition. The $\Delta r h 2$ mutant was more sensitive to photoinhibition or showed some other defect in PSII when grown under control and low light conditions in comparison to the $\Delta r h 1$ and $\Delta r h l / 2$ mutants. On the other hand, the $\Delta r h 1 / 2$ double mutant was more resistant to photoinhibition with the highest $\mathrm{F}_{\mathrm{v}} / \mathrm{F}_{\mathrm{m}}$ values under low light and salt stress conditions (Fig. 5b).

The effective photochemical quantum yield $\left(\Phi_{\mathrm{PSII}}\right)$ measures the proportion of light absorbed by chlorophylls associated with PSII that is used in photochemistry and it can provide a measure of the rate of linear electron transport. The double mutant $\Delta r h l / 2$ had the lowest $\Phi_{\mathrm{PSII}}$ under control 
Fig. 4 Gametophyte growth of WT, $\Delta r h 1, \Delta r h 2$ and $\Delta r h 1 / 2$ under the standard conditions. a Two-week-old spot inocula grown on minimal BCD medium (left panel) and isolated one-month-old gametophores (right panel). b Detailed view of isolated filaments showing accelerated protonemata side branch growth in $\Delta r h 2$ and aberrant protonemata development in $\Delta r h 1 / 2$ compared to WT and $\Delta r h 1$. c Left side graph: the area of ellipse surrounding 2-week-old inocula from individual strains as depicted on a, Middle graph: the length of gametophores measured from the base to the apex of stems. Right side graph: the summed length of first ten side branches counted from the tip of the primary filament. Measurements were performed using PROMICRA QuickPHOTO MICRO 3.0 software. For each strain, twelve plants/gametophores/ filaments taken from four independent cultures were measured $(\mathrm{n}=12)$. Statistical significance (a-c) of the means was assessed at $95 \%$ confidence. Analysis of variance (ANOVA) and least significant difference (LSD) was performed in multiple sample comparison. Scale bars: $5,0 \mathrm{~mm}$ in a left panel, $2.0 \mathrm{~mm}$ in a right panel, $1.0 \mathrm{~mm}$ in $(\mathbf{b})$

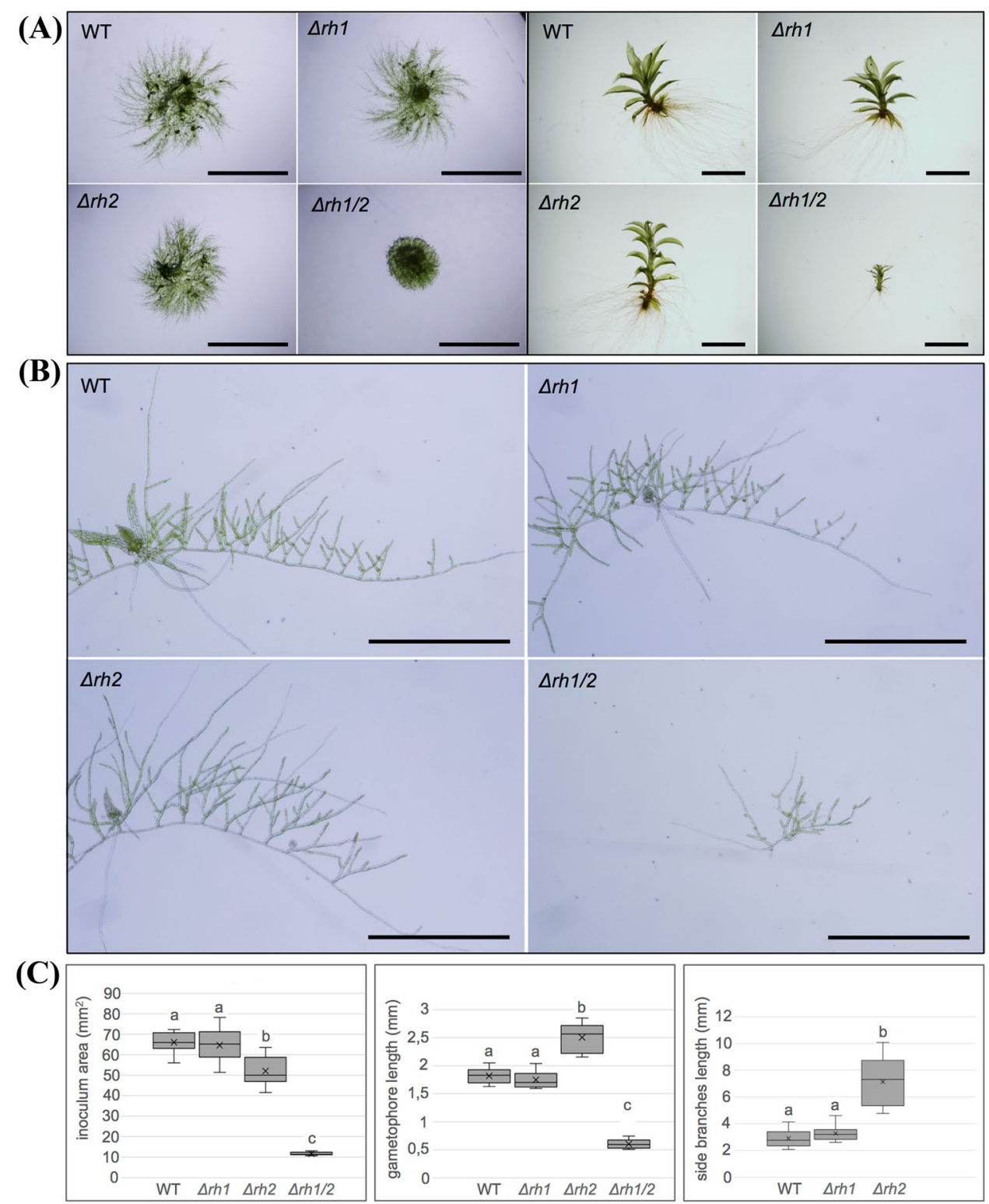

conditions, while this same parameter was the highest under salt stress condition. This discrepancy was caused by the fact that $\Phi_{\text {PSII }}$ decreased under salt stress conditions in all genotypes in comparison to control condition, while, in $\Delta r h l / 2$, it was kept the same (Supplementary Fig. 5c).

The photochemical quenching (qP) indicates proportion of PSII reaction centres that are open and the lower values indicate increased excitation pressure on PSII. This was again found in the $\Delta r h 2$ mutant under control conditions, which is in accordance with decreased $\mathrm{F}_{\mathrm{v}} / \mathrm{F}_{\mathrm{m}}$ values. More oxidized PSII centres were found in the $\Delta r h 1 / 2$ mutant under high light conditions. The non-photochemical quenching parameter (NPQ) is related to heat dissipation in PSII. In $\Delta r h 2$ mutants, the values were lower under high light and salt stress conditions. Increased NPQ was found in the $\Delta r h 1 / 2$ double mutant under control and high light conditions, but during salt stress conditions, the parameter was the lowest (Supplementary Fig. S11).

In conclusion, $\Delta r h l$ and WT genotypes do not differ in any photosynthetic parameters and seem to be very similar under different growth conditions, while the $\Delta r h 2$ and $\Delta r h 1 / 2$ mutants differed from WT and $\Delta r h 1$, often exhibiting opposite trends relative to each other.

To further explore change in photosynthetic performance of the helicase mutants, we performed anatomical and ultrastructural observations of phyllid chloroplasts. A closer examination of plastid morphology in plants growing under standard conditions revealed morphological changes in both $\Delta r h 2$ and $\Delta r h 1 / 2$ mutants. Compared to WT and $\Delta r h 1$, plastids in $\Delta r h 2$ and $\Delta r h 1 / 2$ are round-shaped with increased width and a visibly larger content of starch grains. (Fig. 6a). The ultrastructural observations of plastids further 
(A)

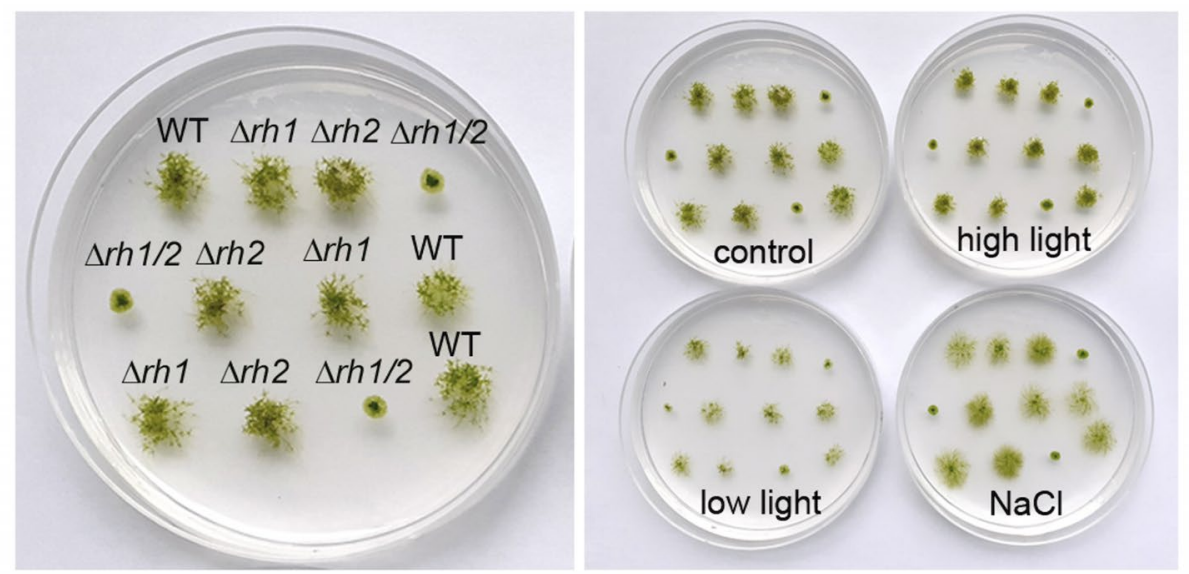

(B)
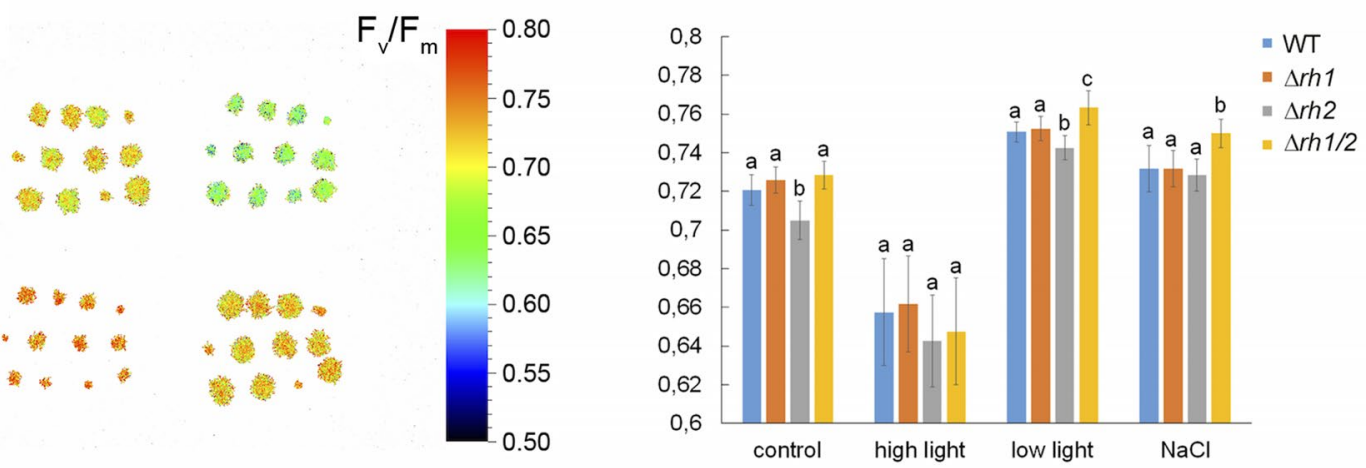

(C)

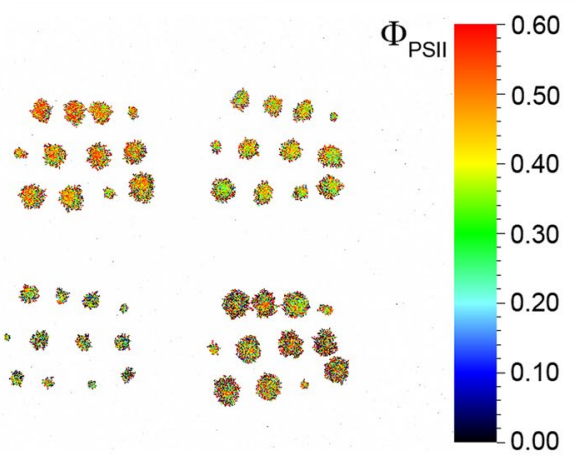

Fig. 5 Chlorophyll fluorescence imaging and quantification. a Plant distribution on Petri dish (left) and Petri dishes with individual treatments. b Maximum quantum yield of PSII (Fv/Fm). c Effective photochemical quantum yield of PSII $\left(\Phi_{\text {PSII }}\right)$. Representative images with scales on the left in $\mathbf{b}$ and $\mathbf{c}$ match plant distribution in four plates/

demonstrated the over-accumulation of starch in $\Delta r h 2$ and $\Delta r h 1 / 2$ mutants compared to WT. On the other hand, the plastid internal membrane system remained well organized in the mutants and we did not observe any abnormalities in plastid stroma (Fig. 6b).

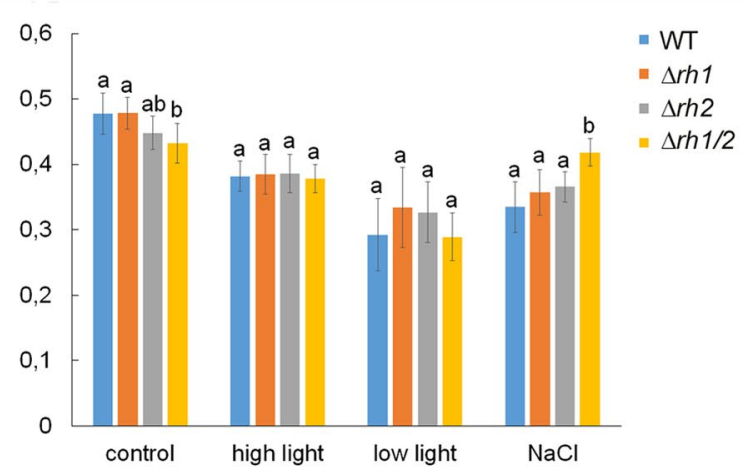

conditions as shown in $\mathbf{a}$, on the right, mean values \pm SD $(n=12)$ are shown. For each strain and condition, twelve plants from four independent cultures were measured. Different letters indicate significant differences at $P<0.05$ within individual treatment (ANOVA, Tukeytest)

\section{P. patens $\Delta r h 2$ and $\Delta r h 1 / 2$ display fertility and sporophyte development impairments}

To evaluate the impact helicase gene deletion on fertility and sporophyte development in $\Delta \mathrm{r} h 1, \Delta \mathrm{r} h 2$ and $\Delta r h 1 / 2$, we exposed them to the standard sexual reproduction procedure (Perroud et al. 2011). In three independent culture replications, WT, $\Delta r h 1, \Delta r h 2$ and $\Delta r h 1 / 2$ produced similarly gametangia after 3 weeks in inductive conditions (Fig. 7a-d). 
(A)
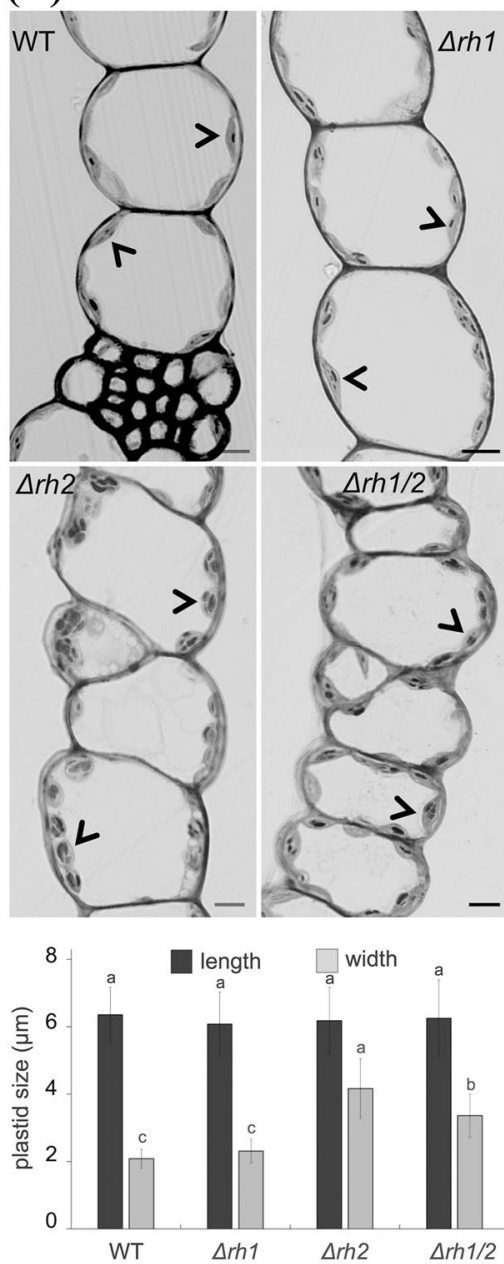

(B)

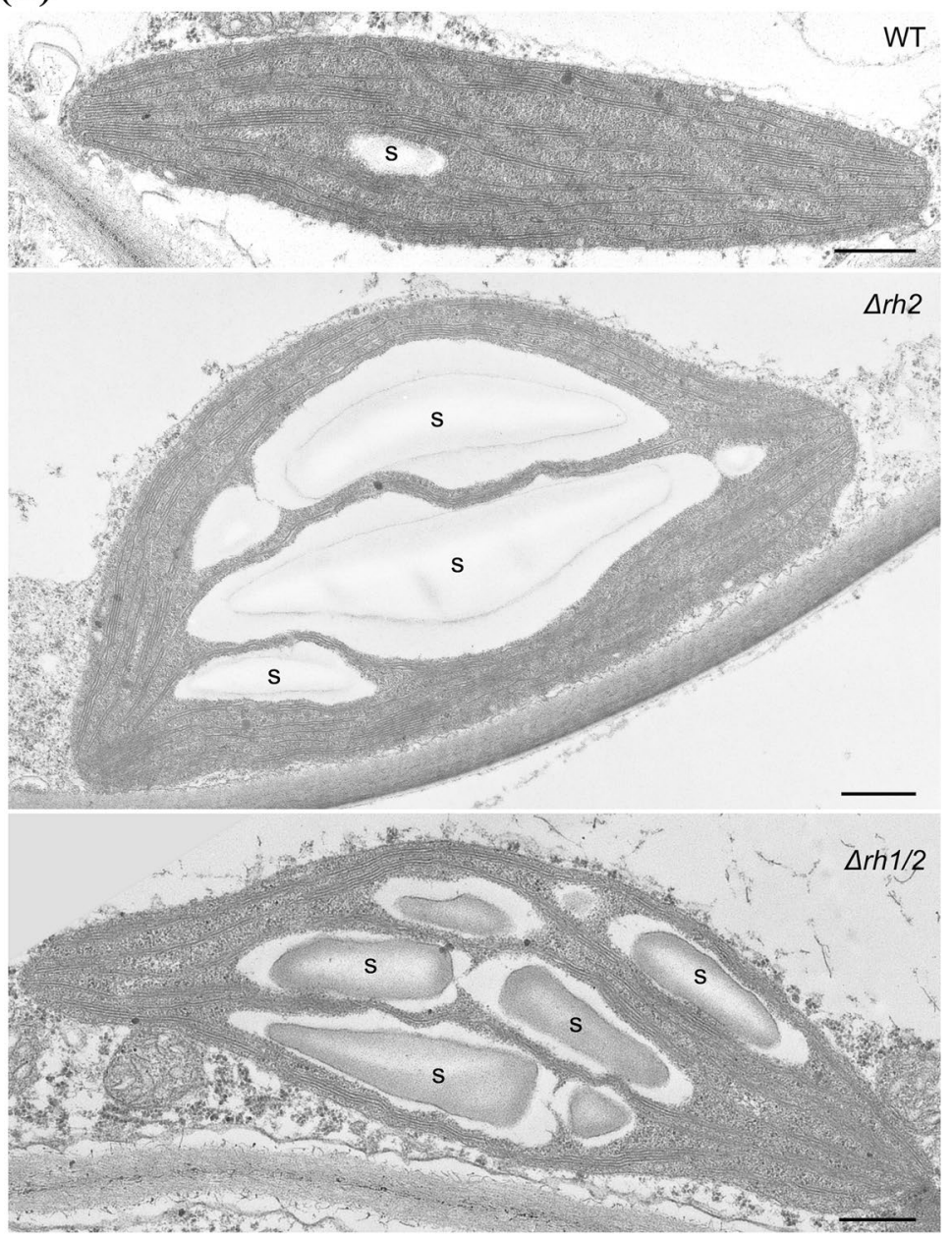

Fig. 6 Chloroplast morphology. a Semithin sections of Physcomitrium patens phyllids from one month old gametophores grown under standard conditions. Plant genotypes are indicated in the individual panels. Each arrowhead points to an individual plastid. Starch grains appear as dense structures inside the plastids. Plastid size is represented by length and width values in the graph below. One hundred plastids from each genotype were measured. Different letters indicate significant differences at $P<0.05$ within individual treatment (ANOVA, Tukey-test), $(\mathrm{n}=100)$. b Representative transmision electron micrographs of plastids from WT, $\Delta r h 2$ and $\Delta r h 1 / 2$ phyllids. Starch grains are indicated by s. Scale bars: $5 \mu \mathrm{m}$ in a, $500 \mathrm{~nm}$ in b
After 5 weeks of inducing conditions, green sporophytes were observed in WT, $\Delta r h 1$ and $\Delta r h 2$ (Fig. 6e-g) as $\Delta r h 1 / 2$ did not display sporophyte (Fig. 7h). After nine or 14 of weeks in inductive conditions, $\Delta r h l / 2$ remained sporophyteless, an indication that these two specific RNA helicases are either involved in sexual reproduction or/and sporophyte development. WT, $\Delta r h 1$ and $\Delta r h 2$ brown sporophyte (Fig. 7i-k) (Hiss et al. 2017) number and size were analyzed after 9 weeks in inductive conditions. $\Delta r h 2$ cultures diverged clearly from WT and $\Delta r h 1 . \Delta r h 2$ fertility, as measured by the number of sporophytes per gametophore, was reduced to $33 \%$ compared to $77 \%$ and $71 \%$, respectively, in WT and $\Delta r h 1$ (Fig. 7l). Also, $\Delta r h 2$ sporophyte size, measured as diameter of the capsule, was consistently reduced by 10 to $20 \%$ across replica compared to either WT or
$\Delta r h 1$ (Fig. $7 \mathrm{~m}$ ). The reduction in sporophyte number and size further implicates a functional role for RNA helicase in both sexual reproduction and sporophyte development in $P$. patens. We subsequently evaluated spore germination from selfed sporophyte of WT, $\Delta r h 1$ and $\Delta r h 2$. The three different spore types germinated into normal looking sporelings (Supplementary Fig. 11a-c). However, germination rates differed. WT and $\Delta r h l$ spore sets from multiple sporophytes displayed a mean germination rate of 80 and $82 \%$, respectively, a value range in accordance with previous observations for WT spore germination after 1 week of growth (Engel 1968; Perroud et al. 2019). In contrast, the $\Delta r h 2$ mean spore germination rate was reduced to $49 \%$ and spore sets from different sporophytes displayed a highly variable germination rate ranging from 2 to $75 \%$ (Supplementary 

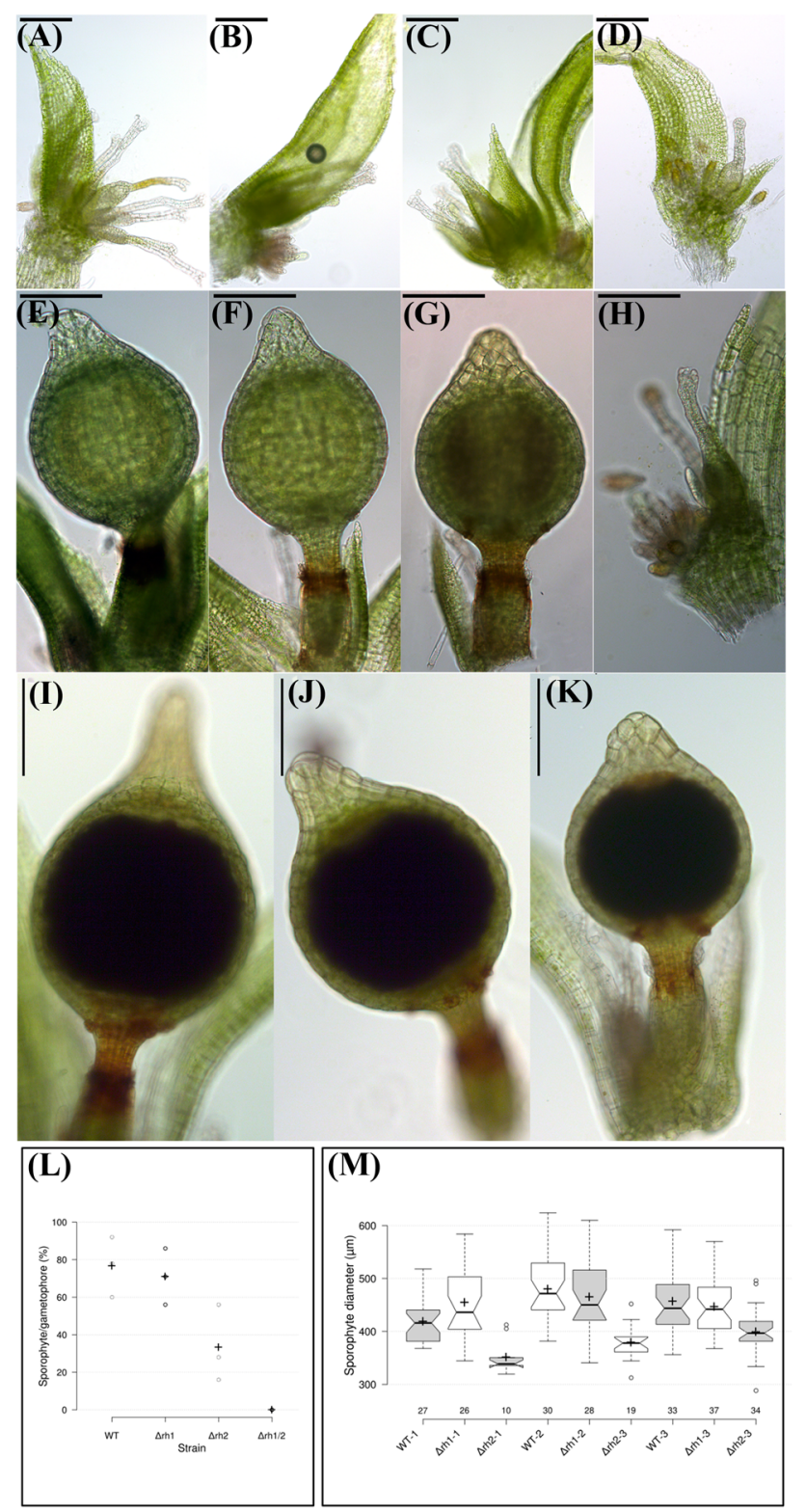

Fig. 7 Sporophyte formation in WT, $\Delta r h 1, \Delta r h 2$ and $\Delta r h 1 / 2$. Physcomitrium patens gametophore apices of plants grown 35 days in $\mathrm{LD}$ at $22{ }^{\circ} \mathrm{C}$ followed by either 21 days in SD at $15^{\circ} \mathrm{C}(\mathbf{a}-\mathbf{d}), 35$ days in $\mathrm{SD}$ at $15^{\circ} \mathrm{C}$ (e-h) or 61 days in SD at $15^{\circ} \mathrm{C}(\mathrm{g}-\mathbf{i})$. These pictures are representative of more than 600 gametophore apices grown in three independent sporulation experiments. After 21 days in cold conditions, gametangia are detectable in mutant plants in similar time frame in contrast to WT plants. a WT. b $\Delta r h 1$. c $\Delta r h 2$. d $\Delta r h 1 / 2$. After 35 days in inducible conditions, green sporophytes are observable on WT, $\Delta r h 1$ and $\Delta r h 2$ apices, but not on $\Delta r h 1 / 2$. e WT sporophyte. $\mathbf{f} \Delta h 1$ sporophyte. g $\Delta r h 2$ sporophyte. $\mathbf{h} \Delta r h 1 / 2$ apex with unfertilized archegonia. After 61 days in cold conditions, brown sporophytes were observed on WT, $\Delta r h 1$ and $\Delta r h 2$ apices. $\mathbf{i}$ Wild-type brown sporophyte. $\mathbf{j} \Delta r h l$ brown sporophyte. $\mathbf{k} \Delta r h 2$ brown sporophyte. Bar in all pictures: $200 \mu \mathrm{m}$. I Fertility rate expressed in \% of gametophores forming a sporophyte. Each dot represents an independent sporulation experiment average with $\mathrm{n}=75-125$. The black cross represents the average value of the triplicate. $T$-test indicates that $\Delta r h 2$ is significantly different from either WT or $\Delta r h l\left(p<10^{-3}\right)$. $\mathbf{m}$ Box plot diagram showing sporophyte diameter distribution ( $\mathrm{n}$ indicated along the $\mathrm{y}$ axis) in three independent sporulation experiments (1-3). $T$-test results indicate that $\Delta r h 2$ dimensions are significantly different from either WT or $\Delta r h l$ in three independent biological replica $\left(p<10^{-3}\right)$. The plot was generated using the online tool BoxPlotR: a web-tool for generation of box plots (http://shiny.chemgrid.org/boxplotr/)
Fig. S12d). Morphologically, WT and $\Delta r h 1$ spores were undistinguishable in appearance (round to slightly ovoid with a regular surface sporopollein deposit) with a diameter of $31.25 \pm 2.74 \mu \mathrm{m}$ and $29.94 \pm 3.04 \mu \mathrm{m}$, respectively (Supplementary Fig. S13, a-h). $\Delta r h 2$ spore size distribution presented a larger variation that appeared to be dependent on the specific sporophyte analyzed (Supplementary Fig. $\mathrm{S} 13, \mathrm{~g}-\mathrm{p}$ and $\mathrm{q})$. Overall, $\Delta r h 2$ displayed a smaller average spore size with $28.1 \pm 4.99 \mu \mathrm{m}$. Additionally, spore not only ranged from mature WT looking spores (Supplementary Fig. S13, i) to very small with a normal surface structure (Supplementary Fig. S13, j, m) but also displayed collapsed aspect with strong alteration of the spore surface (Supplementary Fig. S13, o, p).

To better understand the origin of $\Delta r h 1 / 2$ self-sterility, we conducted crossing experiments with either known fertile males with a visually tractable marker or a sterile male mutant. Using standard co-cultivating procedure and time-extended cultures, no sporophyte development was observed on $\Delta r h 1 / 2$ gametophores when co-cultivated with Vx-red (Perroud et al. 2011) or Re-mCherry (Perroud et al. 2019) as these two well-characterized fertile strains selfed normally in the co-cultures (sporophytes forming on $100 \%$ of gametophores with more than 15 phyllids). Hence $\Delta r h 1 / 2$ archegonia, albeit displaying a normal morphological development are apparently sterile. In parallel, $\Delta r h 1 / 2$ was co-cultivated with $c c d c 39$, a male sterile mutant with fully functional archegonium (Meyberg et al. 2020). Similarly to selfing trials, $\Delta \mathrm{r} h 1 / 2$ gametophores did not form any sporophyte and a single sporophyte was detected on $c c d c 39$. Progeny analysis indicated that sporophyte was a very rare $c c d c 39$-selfed sporophyte. These results indicate that $\Delta r h 1 / 2$ spermatozoids, however present, are infertile.

\section{Discussion}

$P p$ RH1 and $P p$ RH2 proteins are members of the DEAD-box RNA helicases and contain a C-terminal GUCT domain. These proteins, together with their GUCT-containing orthologues, constitute a clearly separated and distinct major group that branches deeply in the phylogenetic tree of Viridiplantae DEAD-box RNA helicases (Fig. 1), suggesting a common and conserved function for these proteins. Using mass spectrometry analysis, GUCT was previously identified as a nucleolar protein domain in humans (Andersen et al. 2002). In the present study, we show that $P p$ RH1 localizes to the nucleus, as does the A. thaliana orthologue AtRH7 (Lorković et al. 1997), providing experimental validation for the predicted localization of GUCT-containing DEAD box RNA helicase to this organelle. GUCT domains appear to be present only in proteins containing domains with annotations related to RNA biology and mainly restricted to 
eukaryotic proteins, the latter also supported by a previous in silico analysis (Staub et al. 2004). Information regarding the function of the GUCT domain is currently absent from the scientific literature. The GUCT domain of the human ATP-Dependent RNA Helicase DDX50 (RH-II/Gu $\beta$ ) protein adopts the RNA recognition (RRM) fold (Ohnishi et al. 2009), however, the critical amino acids, documented to be necessary for binding and coordinating RNA, are absent, and it has been suggested that the domain, in DDX50, might rather function in general protein binding. Functional studies of human DDX50 in HeLa cells have shown that the protein is necessary for cell growth and cell cycle progression $(\mathrm{Ou}$ et al. 1999) and that the protein is involved in ribosomal RNA production (Henning et al. 2003). Similarly, the AtRH7 protein, predominantly expressed in cells and in regions of cells undergoing active cell division, is also involved in ribosomal RNA production in A. thaliana (Huang et al. 2016). Interestingly, our analysis shows that $P p R H 1$ accumulates to a higher level in the cells of the growing protonemal filaments (Fig. 3). Combined, these results suggest that the function of GUCT-containing RNA helicases is associated with cells actively expanding in mosses.

The functional characterization of plant DEAD-box RNA helicases belonging to sub-clade I is still limited to A. thaliana (Lorković et al. 1997; Kim et al. 2013; Huang et al. 2016; Liu et al. 2016) and P. patens (this work). In addition, $P p R H 1$ and $P p R H 2$ represent paralogues in the moss in contrast to the single orthologues identified in A. thaliana, O. sativa, M. polymorpha and M. viride (Fig. 1, Supplementary Fig. S1), which raises questions about their functional conservation. When it comes to biological outcome of their molecular function (r-RNA processing and hence ribosome assembly), diverse developmental processes appear affected by the A. thaliana ortholog AtRH7. atrh7 mutants display reduced fertility, shorter siliques with shrunken seeds and variable defects in embryo patterning (Huang et al. 2016; Liu et al. 2016). It has been proposed that a developmental role of AtRH7 might be associated with auxin signaling via translational control of auxin response factors (ARFs) (Huang et al. 2016). This hypothesis was based on observations where ribosome protein mutants that exhibit reduced ARF content, and hence altered auxin response, show similar phenotypes as atrh7 mutants (Rosado et al. 2012; Huang et al. 2016). In P. patens, the absence of $P p R H I$ had no detectable effect on growth and development throughout the moss life cycle. This is in sharp contrast with diverse phenotypic consequences of the loss of $\mathrm{PpRH} 2$, or both genes in the double mutant, which indicates intricate functional interconnection. While, in $\Delta r h 2$, the protonemal filaments show accelerated side-branch growth with actively expanding caulonemal cells, the protonematal growth and caulonemal development is strongly reduced in the $\Delta r h 1 / 2$ double mutant. Although auxin signaling has been attributed to control of protonemata growth and development in numerous studies (reviewed by Thelander et al. 2018), a link between auxin and ribosomal RNA processing in representatives of early diverging land plants is still missing. Similarly, as in protonemata, deletion of $P p R H 2$ alone, and both $P p R H 1$ and $P p R H 2$ in the double mutant, caused opposite rather than cumulative effects on gametophore growth (Figs. 4, S6). One common feature in $\Delta r h 2$ and $\Delta r h 1 / 2$ mutants was altered plastid morphology and increased accumulation of starch (Fig. 6). Impaired starch degradation has been recently reported in $P$. patens glucan, water dikinase (Ppgwd) mutants (Mdodana et al. 2019), however, in that case, gametophore formation was almost completely blocked. Despite dramatic developmental differences between $\Delta r h 1, \Delta r h 2$ and $\Delta r h 1 / 2$ mutants, their photosynthetic performance is rather similar, which indicates that chloroplast biogenesis is not a primary cause of the mutant phenotypes.

In A. thaliana, the atrh 7 mutant exhibits considerably increased developmental abnormalities after prolonged growth at low temperature (Huang et al. 2016; Liu et al. 2016). This effect was associated with a cold-induced role of AtRH7 in rRNA processing. In $P$. patens, $24 \mathrm{~h}$ cold treatment had no considerable effect on $P p R H 1$ and $P p R H 2$ transcript levels and long-term cultivation at $10{ }^{\circ} \mathrm{C}$ did not change phenotypical characteristics of the mutants gametophores. In addition, the $P p R H 1$ and $P p R H 2$ deletion mutants showed a similar growth response as WT when cultivated under lowlight, high-light or osmotic stress conditions. This indicates that the role of $P p R H 1$ and $P p R H 2$ is associated with default developmental control rather than stress-induced protective mechanisms. Hypothetically, cold responsiveness function has been acquired during the evolution of A. thaliana ortholog AtRH7 as a novel element in addition to it's developmental role. The DEAD-box RNA helicase elF4A protein, which consists of the helicase core only, was recently reported to be involved in stress management and cell cycle progression in $P$. patens (Tyagi et al. 2020). The difference in $P p \mathrm{RH} 1 / P p \mathrm{RH} 2$ and elF4A response to stress suggests functional specialization of these two groups of DEAD-box RNA helicases in $P$. patens and is also supported by the phylogenetic analysis that clearly sorts the $P p \mathrm{RH} 1 / P p \mathrm{RH} 2$ and elF4A proteins into distinct clades (Supplemetary Fig. S1).

Finally, $P p$ RH1 and $P p$ RH2 genetic analysis revealed an intriguing functional pattern The two paralogs $P p$ RH1 and $P p$ RH 2 are $82 \%$ identical and possess an identical domain topology. But, their specific deletion generates two different phenotypes. $\Delta r h l$ does not display any morphological detectable divergence to WT. In contrast, $\Delta r h 2$ presents developmental differences with WT in virtually all gametophytic and sporophytic tissues of P. patens. Additionally, $\Delta r h 1 / 2$ showed even more severe growth defects than $\Delta r h 2$ and was completely sterile. This implies that, despite being nonessential for normal plant development, $P p$ RH1 
possesses a partial functionality in the $\Delta r h 2$ background. Two potential hypotheses could explain these observations. Perhaps the accumulated amino acid differences between the two paralogues reflect the beginning of neo-functionalization, in which $P p R H 1$ has acquired a novel function not detected by our analysis and is already sufficiently diverged to only partially complement $P p \mathrm{RH} 2$ absence. Alternatively, $P p$ RH1 is in an early phase of decay that will ultimately lead to the formation of a true pseudogene. This second hypothesis is further supported by the differential expression patterns of these two genes. PpRHI transcripts accumulate to higher levels than those of $P p R H 2$ in all investigated tissues. This could represent a loss of $P p R H 1$ regulation either through transcript stability or promoter regulation, a step in the process of gene degeneration toward the formation a fully inactive pseudogene.

\section{Material and method}

\section{Bioinformatic analysis}

RNA helicases from $C$. reinhardtii (v.5.5), M. polymorpha (v3.1), P. patens (v3.3), O. sativa (v7_JGI), A. thaliana (TAIR10) and $S$. lycopersicum (iTAG2.4) were identified and downloaded from the Phytozome12 database using Pp3c20_20710 (PpRH1) as query in pBLAST searches. $M$. viride RNA helicase sequences were downloaded from the MVGE (v1.0) database at http://www.elabcaas.cn/alga/ index.html (Liang et al. 2020) using the same approach. Each of the sequences was submitted to Pfam (v.33.1) to identify and annotate domain modules and only domains with significant annotations and containing the DEAD signature sequence in motif II (Fig. 1a) in the helicase core were further selected (Supplementary Data S1). The helicase core (e.g. the subsequence spanning from 10 amino acids upstream to 10 amino acid downstream of the DEAD and helicase_C domains, respectively) was further extracted and aligned using MAFFT (v.7) and the E-Ins-I algorithm (Katoh and Standley 2013). Reconstruction of maximum likelihood (ML) phylogeny of the helicase core was performed using neighbor joining and the WAG substitution model in the CLC genomic Workbench package with 1000 bootstrap iterations. Subcellular localization signals were predicted using the Plant-mPLoc server (Chou and Shen 2010) at http://www.csbio.sjtu.edu.cn/bioinf/plant-multi/.

\section{Plant material and plant culture}

Physcomitrium patens (previously known as Physcomitrella patens) (Medina et al. 2019) Gransden wild-type (WT), pedigree Gd_JP_St Louis (Haas et al. 2020) was used as starting plant material for this study. Maintenance and amplification tissue culture for the WT and mutant strains were performed either directly on BCDA medium (Cove et al. 2009) for spot inoculum or on cellophane overlaying the medium for blended tissue used for protoplasting. Standard culture conditions are long-day light $(16 \mathrm{~h}$ light / $8 \mathrm{~h}$ darkness) with a light intensity of $70 \mu \mathrm{mol} \mathrm{s}^{-1} \mathrm{~m}^{-1}$ at a constant temperature of $24^{\circ} \mathrm{C}$. All vegetative tissue phenotypic analyses were performed on BCD medium (Cove et al. 2009). Plants harvested for RT-qPCR analyses were grown under standard conditions unless otherwise specified. For long-term stress treatments, spotted cultures were cultivated for 2 weeks on BCD media under long-day light with intensities 5 and $140 \mu \mathrm{mol} \mathrm{s}{ }^{-1} \mathrm{~m}^{-1}$ at $24{ }^{\circ} \mathrm{C}$ and on media supplemented with $90 \mathrm{mM} \mathrm{NaCl}$, respectively. For short-term stress treatments, blended protonemata were first grown on BCD media overlaid with cellophane for 2 weeks under standard conditions. Then, the cultures were transferred to fresh BCD media and media supplemented with $10 \mu \mathrm{M}$ abscisic acid (Sigma-Aldrich). Part of the cultures was transferred to a $10{ }^{\circ} \mathrm{C}$ bath. Plants were thusly treated for $24 \mathrm{~h}$ before harvesting for further analyses.

Physcomitrium patens culturing, both WT and mutants, was performed to access fertility as previously described (Perroud et al. 2011, 2019). Shortly, after 5 weeks of growth in standard conditions, single or double mutant strain cultures were transferred to gametangia inductive condition (Hohe et al. 2002), at $15^{\circ} \mathrm{C}$ with a short day light cycle of $8 \mathrm{~h} \mathrm{light} / 16 \mathrm{~h}$ dark regime with a reduced fluence rate of $20 \mu \mathrm{mol} \mathrm{m}^{-2} \mathrm{~s}^{-1}$ white light, for the rest of the experiment. Two weeks later, plants were watered with sterile water and put back in inductive conditions. The presence of gametangia was evaluated after 3 weeks in inductive conditions and the standard green sporophyte observation time point was performed 2 weeks later (i.e. after 5 weeks). Brown sporophytes were counted on gametophores displaying more than 15 phyllids, the percentage of sporophyte-bearing gametophores was used as proxy for fertility. Sporophyte diameter was measured at the middle of the sporogenic domain of the sporophyte, perpendicular to its axis of development. For spore germination assay, sporophytes were harvested under sterile conditions and were stored for at least a week in the dark at $4{ }^{\circ} \mathrm{C}$ before evaluation of spore germination (Perroud et al. 2019).

\section{Plasmid vector constructions}

Plasmid vectors were constructed using recombinationbased In-Fusion ${ }^{\circledR}$ Cloning technology (Takara Bio Europe, SAS, France) according to the manufacturer's instructions. The sequences of the oligonucleotide primers used in vector constructions are listed in Supplementary Table S3. Final plasmid constructs were verified by restriction digest analysis and sequencing. 
The two-knockout (KO) vectors pBHRF_hel1_KO and pBNRF_hel2_KO (Supplementary Fig. S14) were generated to delete the Pp3c20_20710 and Pp3c10_20840 genes, respectively. To generate the vector pBHRF_hel1_KO, the 5' and $3^{\prime}$ targeting sequences (TGS) were PCR-amplified with genomic DNA extracted from WT P. patens Gransden using primer pairs SP_5'_ARH1 and ASP_5'_ARH1, and SP_3' ARH1 and ASP_3'_ARH1, respectively. The PCR-amplified $5^{\prime}$ and $3^{\prime}$ TGSs were cloned sequentially into NruI- and SpeIlinearized plasmid pBHRF (Schaefer et al. 2010), respectively, resulting in vector pBHRF_hel1_KO. To generate the vector for pBNRF_hel2_KO, the 5' and 3' TGS were PCR amplified using primer pairs SP_5'_ARH2 and ASP_5' ARH2, and SP_3'_ARH2 and ASP_3'_ARH2, respectively. The PCR-amplified 5' and 3' TGSs were inserted sequentially into plasmid pBNRF (Schaefer et al. 2010) linearized by inverse PCR using primer sets pBHRF-5In-SP and pBHRF-5In-ASP, and pBHRF-1-SP and pBHRF-1-ASP to clone the $5^{\prime}$ and $3^{\prime}$ TGS fragments, respectively, resulting in KO vector pBNRF_hel2_KO.

To identify the subcellular localization of the $P p$ RH1 protein, we generated the knock-in vector, phel1_GFP_KI (Supplementary Fig. S14), designed to insert the coding sequence of a trimeric enhanced green fluorescent protein (3XmGFP) in-frame with the $3^{\prime}$ end of PpRH1. Additionally, the fluorescent tag was separated from the native protein by a linker sequence corresponding to amino acids Gly-GlyGly-Gly-Ser. Prior to generating the final phel1_GFP_KI vector, the 3xmGFP fragment was PCR amplified from vector p3XmEGFP-L5L4 (generous gift from M. Bezanilla and L. Vidali) using primers Ppf1 and Ppf 2 and then cloned into vector pBHRF (Schaefer et al. 2010) using NruI and XhoI to generate vector p3xGFP-LoxP_Hygro_LoxP. The phel1_GFP_KI vector was then constructed in the following way: the 5' TGS was first PCR amplified from gDNA extracted from WT $P$. patens Gransden using primer pair SP_5'-KI and ASP_5'-KI. The reverse primer (ASP_5'-KI) was designed to harbour a $5^{\prime}$ extension to add the 15 -bp linker sequence to the $3^{\prime}$ end of the amplified product. The resulting PCR fragment (1348 bp) was sub-cloned into the Zero Blunt PCR vector (Invitrogen) generating plasmid pPCR_5'TGSLinker. Finally, the 5' TGS fragment was PCR amplified with pPCR_5'TGSLinker DNA as template using primer pairs SP_5'Inf-KI and ASP_5'Inf-KI containing 5' 15-bp extensions to allow In-Fusion cloning into vector p3xGFP-LoxP_Hygro_LoxP vector. Similarly, primer pair SP_3'Inf-KI and ASP_3'Inf-KI were used to PCR amplify the $3^{\prime}$ TGS using $P$. patens WT gDNA as the template. The resulting $5^{\prime}$ and $3^{\prime}$ TGSs fragments were In-Fusion cloned sequentially into p3xGFP-LoxP_Hygro_LoxP, linearized with NruI and SpeI, respectively, leading to the final vector phel1_GFP_KI.

\section{Plant transformation}

Physcomitrium patens protoplast production and transformation was performed according to Schaefer and Zrÿd (Schaefer and Zrÿd 1997) as modified by Cove and collaborators (Cove et al. 2009). Plasmids pBHRF_hel1_KO, pBNRF_hel2_KO and phel1_GFP_KI were linearized with restriction enzyme pairs BmrI/PacI, SmaI/PacI and HpaI/PmlI, respectively (Supplementary Fig. S14). The double mutant $(\Delta r h 1 / 2)$ was generated by transforming pBHRF_hel1_KO into the $\Delta$ rh2/cre background (Supplementary Fig. S5). Fifteen $\mu \mathrm{g}$ of linearized plasmid DNA was used per transformation. Briefly, transformed protoplast regeneration and selection was performed by transferring the tissue to different media according to the following sequence: 7 days of protoplast regeneration on protoplast regeneration medium for the bottom layer (PRMB), 7 days of selection on BCDA medium supplemented with the appropriate antibiotic, 14 days of growth on BCDA medium, and 7 days on BCDA medium supplemented with the appropriate antibiotic. Resistant plants were individually transferred to fresh BCDA medium and used for genotyping after sufficient growth.

The Cre recombinase procedure to remove the resistant marker from the primary transformant was performed as described previously (Trouiller et al. 2006) with minor modifications. Transformed tissue was grown as the WT, and protoplast production and transformation was performed using $20 \mu \mathrm{g}$ of the plasmid pAct-Cre (Trouiller et al. 2006). Diluted protoplast suspensions were plated on cellophanecoated medium (approximately 25,000 counted protoplasts per 9-cm Petri dish) to avoid mixing of regenerated plants. Protoplast regeneration and the test procedure were performed as follows: (1) 4 days of protoplast regeneration on PRMB medium; (2) 4 days of protoplast growth on BCDA medium; (3) individual plants transferred to fresh BCDA medium and growth for 8 days and (4) replica plating of each individual plant onto BCDA medium and BCDA medium supplemented with the appropriate antibiotic. Strains showing loss of antibiotic resistance were selected and grown until sufficient tissue was available for PCR genotyping.

\section{Molecular characterization of the $P$. patens mutants}

All mutants were subjected to three rounds of PCR genotyping (Supplementary Fig. S3), using the Phire Plant Direct PCR kit (Thermo Fisher Scientific, Schwerte, Germany) according to the manufacturer's instructions. The primer sequences used for genotyping are provided in Supplementary Table $\mathrm{S} 3$.

The $\Delta r h 1, \Delta r h 2$ and $\Delta r h 1 / 2$ mutants were first genotyped for loss of locus using primers specific to the deleted gene (for Pp3c20_20710, primers F-KO1_GS and R-KO1_GS; 
for Pp3c10_20840, primers F-KO2_GS and R-KO2_GS). All plants displaying loss of the WT locus were further genotyped for $5^{\prime}$ and $3^{\prime}$ targeting events. 5' and $3^{\prime}$ targeting for putative Pp3c20_20710 deletion mutants $(\Delta r h l)$ were performed using primers setts F-KO1_GT and 35S$\mathrm{R}$, and Term-F and R-KO1_GT, respectively. For putative Pp3c10_20840 deletion mutants ( $\Delta r h 2)$, primer sets F-KO2_ GT and 35S-R and Term-F and R-KO2_GT were used for 5' and $3^{\prime}$ targeting, respectively. Plants positive for both $5^{\prime}$ and $3^{\prime}$ targeting were finally genotyped to identify single-copy insertions at the Pp3c20_20710 and Pp3c10_20840 loci using primers F-KO1_GT and R-KO1_GT and F-KO2_GT and R-KO2_GT, respectively. Genotyping for putative double mutants $(\Delta r h 1 / 2)$ was performed as described previously for the single Pp3c20_20710 deletion mutant $(\Delta r h 1)$. Before transformation of $\Delta r h 2 / c r e$ to create $\Delta r h 1 / 2$, the $\Delta r h 2 /$ cre mutant was verified by Southern Blot hybridization. Genomic DNA was extracted using the Nucleon PhytoPure Genomic DNA Extraction Kit (GE Healthcare). Southern hybridization was performed as described by Perroud and Quatrano (2006) using $1 \mu \mathrm{g}$ of XhoI-digested DNA. Two hybridization probes corresponding to the $5^{\prime}$ and $3^{\prime}$ targeting sequences were labelled with digoxigenin using the DIG Probe PCR synthesis kit (Roche) according to the manufacturer's instructions. The construct pBNRF_hel2_KO was used as template for PCR amplification of the probes. The sequences of the primers used to generate the probes (5'TGSp-F/5'TGSp-R and 3'TGSp-F/3'TGSp-R primer sets for the 5'TGS and 3'TGS probes, respectively) are provided in Supplementary Table S3, and the hybridization sites of the probes are shown schematically in Supplementary Fig. S5.

For putative $r h 1-3 x g f p$ mutants, first genotyping was performed to verify insertion of $3 X m E G F P$ using primer pair F-KI_GS and R-KI_GS (Supplementary Fig. S3). Mutant lines showing the expected amplicon size were subjected to a second round of PCR genotyping to verify $5^{\prime}$ and $3^{\prime}$ targeting events using primer pairs F-KI_GT and 35S-R, and Term-F and R-KI_GT, respectively. In the third round of PCR genotyping, primer pairs F-KI_GT and R-KI_GT were used to confirm single copy insertion at the locus.

\section{Reverse-transcriptase quantitative PCR (RT-qPCR)}

Plant material was frozen in liquid nitrogen and stored at $-70{ }^{\circ} \mathrm{C}$ prior to RNA extraction. Total RNA was extracted in three independent biological replicates using either the Plant RNeasy kit (Qiagen) or the Spectrum Plant Total RNA kit (Sigma-Aldrich) according to the manufacturer's instructions. After analysis of RNA purity and integrity 500 or 1000 ng DNaseI-treated RNA was reverse transcribed using either 100 units of SuperScript ${ }^{\mathrm{TM}}$ III reverse transcriptase (Thermo Fisher Scientific) primed with $50 \mu \mathrm{M}$ random hexamers primers at $55^{\circ} \mathrm{C}$ for 60 min or using GoScript ${ }^{\mathrm{TM}}$ Reverse Transcription System (Promega) according to the manufacturer's protocol. Transcript level analysis was performed in triplicate using the HOT FIREPol ${ }^{\circledR}$ EvaGreen ${ }^{\circledR}$ qPCR Mix Plus (ROX) system (Solis Biodyne) on the 7500 Fast Real-Time PCR Systems (ABI) using the following thermal profile for all targets: $95^{\circ} \mathrm{C}$ for 15 min followed by 40 cycles of $95^{\circ} \mathrm{C}$ for $30 \mathrm{~s}, 62^{\circ} \mathrm{C}$ for $20 \mathrm{~s}$, and $72{ }^{\circ} \mathrm{C}$ for $32 \mathrm{~s}$. For one set of experiments, qPCR analysis was performed using the Maxima SYBR Green/ROX qPCR Master Mix system (Thermo Fisher Scientific) at an annealing temperature of $60{ }^{\circ} \mathrm{C}$. Final post-PCR dissociation analysis was included for each run. Mean PCR efficiency values (E) for each targets were determined using the LinRegPCR software v11.0 (Ruijter et al. 2009) and by dilution curves prior to qPCR analysis. Relative transcript levels of targets were normalized to the transcript level of RIBOSOMAL PROTEIN S9 (RSB; Pp3c18_1350V3.1) (Xiao et al. 2011). Fold change expression values were calculated relative to the WT, which was set to 1 , using the Pfaffl method (Pfaffl 2001). The Student's $t$ test was used for statistical analysis (Statgraphics centurion 15.2.05). cDNA targets were amplified using the following gene-specific primer pairs: for $P p R H 1$, Arh1q$\mathrm{F}$ and Arh1q-R; for $P p R H 2$, Arh2q-F and Arh2q-R; and for $P p R S B, \mathrm{RSBq}-\mathrm{F}$ and RSBq-R (Supplementary Table S3).

\section{Chlorophyll fluorescence measurements}

The moss ( $P$. patens) was dark-adapted for $40 \mathrm{~min}$. The Petri dishes were open prior measurements. The chlorophyll $a$ fluorescence was measured using fluorocamera FluorCam 800 MF (Photon System Instruments, Drášov, Czech Republic). Minimal fluorescence $\left(\mathrm{F}_{0}\right)$ was measured at $0.25 \mu \mathrm{mol} \mathrm{m}{ }^{-2} \mathrm{~s}^{-1}$ PAR and $\lambda=620 \mathrm{~nm}$. Then, maximum fluorescence $\left(\mathrm{F}_{\mathrm{m}}\right)$ was measured by a saturation pulse at $3200 \mu \mathrm{mol} \mathrm{m}^{-2} \mathrm{~s}^{-1}$ PAR, $800 \mathrm{~ms}$ duration and $\lambda=450 \mathrm{~nm}$, and the maximum quantum yield (variable/maximum fluorescence, $\left.\mathrm{F}_{\mathrm{v}} / \mathrm{F}_{\mathrm{m}}\right)$ was calculated as $\left(\mathrm{F}_{\mathrm{m}}-\mathrm{F}_{0}\right) / \mathrm{F}_{\mathrm{m}}$. For analysis of the quenching mechanism, actinic light was turned on for $10 \mathrm{~min}\left(70 \mu \mathrm{mol} \mathrm{m} \mathrm{m}^{-2} \mathrm{~s}^{-1}\right.$ PAR, $\left.\lambda=620 \mathrm{~nm}\right)$ and ten saturation pulses were triggered to estimate maximum chlorophyll fluorescence in the light-adapted state $\left(\mathrm{F}_{\mathrm{m}}^{\prime}\right.$, $3200 \mu \mathrm{mol} \mathrm{m}{ }^{-2} \mathrm{~s}^{-1}$ PAR, $800 \mathrm{~ms}$ duration, $\lambda=450 \mathrm{~nm}$ ). The actinic light was then turned off and $\mathrm{F}_{0}{ }^{\prime}$ was measured. The effective photochemical quantum yield of photosystem II $\left(\Phi_{\mathrm{PSII}}\right)$, photochemical quenching $(\mathrm{qP})$ and non-photochemical quenching (NPQ) were calculated according to Maxwell and Johnson (2000). 


\section{Standard microscopy procedure}

Routine tissue check and early phenotype analyses were performed with a Leica S8 APO binocular (Leica, Wetzlar, Germany). Microscopic picture were taken with an upright DM6000 equipped with a DFC295 camera (Leica, Wetzlar, Germany). The Leica Application Suite version 4.4 was used as acquisition tool. Size measurement was performed using the measure tool from Image J1.52t (Rasband 2018) on unmodified primary pictures. Subsequent image processing (brightness and contrast adjustment) was performed with Adobe Photoshop Suite.

\section{Plastid morphology and ultrastructure observation}

For microscopy studies, whole cut gametophores were fixed with $3 \%(\mathrm{w} / \mathrm{v})$ glutaraldehyde and $1 \%$ fresh prepared paraformaldehyde in $100 \mathrm{mM}$ MTSB buffer (Vitha et al. 2000) for three hours and after washing postfixed with $1 \%(\mathrm{v} / \mathrm{v})$ osmium tetroxide in the same buffer for two hours. After dehydration in ethanol, samples were embedded in Spur's resin (Spurr 1969). Semithin (1 $\mu \mathrm{m}$ thick) and ultrathin sections were cut by LKB 8800 Ultratome III. Semithin sections were stained with $1 \%$ toluidine blue 0 in $1 \%$ sodium borate and poststained with $0.1 \%$ aqueous basic fuchsin and examined in an Olympus BX61 epifluorescence microscope with an Olympus UPlanSApo 60X/1.35 Oil objective lens and under bright light illumination. Images were acquired with a Levenhuk M 1400 Plus digital camera and a LevenhukLite software. The size of plastids was analyzed on semi-thin sections using ImageJ software. Ultra-thin Sects. (50 nm thick) were contrasted with $2 \%$ uranyl acetate dissolved in 50\% ethanol and with lead citrate (Reynolds 1963) for $20 \mathrm{~min}$ each and studied in a Jeol $100 \mathrm{CX}$ electron microscope at $100 \mathrm{kV}$.

\section{Confocal microscopy procedure}

Confocal microscopy acquisitions were performed using a Leica TCS SP8X as described (Perroud et al. 2020) with fluorescence excitation and signal acquisition wavelength modifications. For live imaging of $3 \times$ GFP tagged protein, excitation wavelength was set to $489 \mathrm{~nm}$ and the signal acquisition was performed between 510 and $550 \mathrm{~nm}$ using the $\mathrm{HyD}^{\mathrm{TM}}$ detector. The acquisition signal was gated between 0.5 and $6 \mathrm{~ns}$ after the laser pulse. Chloroplast autofluorescence was acquired in parallel using the same excitation wavelength with an acquisition window between 660 and $710 \mathrm{~nm}$ using a standard PMT. For all images scan speed was set $400 \mathrm{~Hz}$ (400 lines/s) at a resolution at $1024 \times 1024$ pixels and four lines averaging per single image was used.
Post acquisition processing was performed using Image J1.52t (Rasband 2018) and assembled in PowerPoint 2016.

Supplementary Information The online version contains supplementary material available at https://doi.org/10.1007/s11103-021-01152-w.

Acknowledgements The authors are thankful to Stefan Rensing for the use of its experimental facilities during this project. The authors thank to Magdalena Bezanilla for the generous gift of the 3XmEGFPL5L4 vector. The authors thank Regine Kahmann and Yanina Rizzi for the generous access to the confocal microscopy equipment at the Max Planck Institute for Terrestrial Microbiology. The authors thank Anna Šoltýsová for assistance with morphological data analysis. We wish to thank Ing. Lucia Olexíková, Ph.D. (IFAGR, Nitra), for helping with TEM procedure. V.D. was supported by the Slovak Research and Development Agency through the grant APVV-17-0570. Finally, the authors wish to thank Robert $\mathrm{C}$. Wilson for critical reading of the manuscript.

Author contributions PFP, VD and JW developed the project and designed the experiments. AEA and RK with the help of JW performed the transformations and the associated molecular analyses. VD and PFP performed the morphological phenotyping and quantification. JJ performed anatomical and ultrastructural observations. AP performed chlorophyll fluorescence imaging and analysis. BB performed stressrelated qPCR experiments and analysis. PFP, VD and JW analyzed data and wrote the article, all other authors read and contributed to previous versions and approved the final version.

Funding Open access funding provided by Inland Norway University Of Applied Sciences. V.D. was supported by the Slovak Research and Development Agency through the Grant APVV-17-0570.

\section{Declarations}

Conflict of interest The authors declared that they have no conflict of interest.

Open Access This article is licensed under a Creative Commons Attribution 4.0 International License, which permits use, sharing, adaptation, distribution and reproduction in any medium or format, as long as you give appropriate credit to the original author(s) and the source, provide a link to the Creative Commons licence, and indicate if changes were made. The images or other third party material in this article are included in the article's Creative Commons licence, unless indicated otherwise in a credit line to the material. If material is not included in the article's Creative Commons licence and your intended use is not permitted by statutory regulation or exceeds the permitted use, you will need to obtain permission directly from the copyright holder. To view a copy of this licence, visit http://creativecommons.org/licenses/by/4.0/.

\section{References}

Andersen JS, Lyon CE, Fox AH, Leung AKL, Lam YW, Steen H, Mann M, Lamond AI (2002) Directed proteomic analysis of the human nucleolus. Curr Biol 12:1-11. https://doi.org/10.1016/ s0960-9822(01)00650-9

Andreou AZ, Klostermeier D (2014) eIF4B and eIF4G jointly stimulate eIF4A ATPase and unwinding activities by modulation of the eIF4A conformational cycle. J Mol Biol 426:51-61. https://doi. org/10.1016/j.jmb.2013.09.027 
Asakura Y, Galarneau E, Watkins KP, Barkan A, van Wijk KJ (2012) Chloroplast RH3 DEAD box RNA helicases in maize and Arabidopsis function in splicing of specific group II introns and affect chloroplast ribosome biogenesis. Plant Physiol 159:961-974. https://doi.org/10.1104/pp.112.197525

Bush MS, Hutchins AP, Jones AME, Naldrett MJ, Jarmolowski A, Lloyd CW, Doonan JH (2009) Selective recruitment of proteins to $5^{\prime}$ cap complexes during the growth cycle in Arabidopsis. Plant J 59:400-412. https://doi.org/10.1111/j.1365-313X.2009.03882.x

Bush MS, Crowe N, Zheng T, Doonan JH (2015) The RNA helicase, eIF4A-1, is required for ovule development and cell size homeostasis in Arabidopsis. Plant J 84:989-1004. https://doi.org/10. 1111/tpj.13062

Bush MS, Pierrat O, Nibau C, Mikitova V, Zheng T, Corke FMK, Vlachonasios K, Mayberry LK, Browning KS, Doonan JH (2016) eIF4A RNA Helicase associates with cyclin-dependent protein Kinase A in proliferating cells and is modulated by phosphorylation. Plant Physiol 172:128-140. https://doi.org/10.1104/pp.16. 00435

Cai J, Meng X, Li G, Dong T, Sun J, Xu T, Li Z, Han Y, Zhu M (2018) Identification, expression analysis, and function evaluation of 42 tomato DEAD-box RNA helicase genes in growth development and stress response. Acta Physiol Plant 40:94. https://doi.org/10. 1007/s11738-018-2665-0

Chou KC, Shen HB (2010) Plant-mPLoc: A top-down strategy to augment the power for predicting plant protein subcellular localization. PLoS ONE. https://doi.org/10.1371/journal.pone.0011335

Cove DJ, Perroud P-F, Charron AJ, McDaniel SF, Khandelwal A, Quatrano RS (2009) The moss Physcomitrella patens: a novel model system for plant development and genomic studies. Cold Spring Harb Protoc 4:69-104. https://doi.org/10.1101/pdb.emo115

Henning D, Rolando B. So, Runyan J, Lester F. Lau, Benigno C. Valdez (2003) Silencing of RNA helicase II/Guo inhibits mammalian ribosomal RNA production. J Biol Chem 278(52):52307-52314

Elzanati O, Mouzeyar S, Roche J (2020) Dynamics of the transcriptome response to heat in the moss, Physcomitrella patens. Int J Mol Sci. https://doi.org/10.3390/ijms21041512

Engel PP (1968) The induction of biochemical and morphological mutants inthe moss Physcomitrella patens. Am J Bot 55:438-446. https://doi.org/10.1002/j.1537-2197.1968.tb07397.x

Fairman-Williams ME, Guenther U-P, Jankowsky E (2010) SF1 and SF2 helicases: family matters. Curr Opin Struct Biol 20:313-324. https://doi.org/10.1016/j.sbi.2010.03.011

Fernandez-Pozo N, Haas FB, Meyberg R, Ullrich KK, Hiss M, Perroud P-F, Hanke S, Kratz V, Powell AF, Vesty EF, Daum CG, Zane M, Lipzen A, Sreedasyam A, Grimwood J, Coates JC, Barry K, Schmutz J, Mueller LA, Rensing SA (2020) PEATmoss (Physcomitrella Expression Atlas Tool): a unified gene expression atlas for the model plant Physcomitrella patens. Plant J 1:165-177. https://doi.org/10.1111/tpj.14607

Haas FB, Fernandez-Pozo N, Meyberg R, Perroud P-F, Göttig M, Stingl N, Saint-Marcoux D, Langdale J, Rensing SR (2020) Single nucleotide polymorphism charting of $P$. patens reveals accumulation of somatic mutations during in vitro culture on the scale of natural variation by selfing. Front Plant Sci 11:813. https://doi. org/10.3389/fpls.2020.00813

Hájek T, Tuittila E-S, Ilomets M, Laiho R (2009) Light responses of mire mosses - a key to survival after water-level drawdown? Oikos 118:240-250. https://doi.org/10.1111/j.1600-0706.2008. 16528.x

Hiss M, Meyberg R, Westermann J, Haas FB, Schneider L, Schallenberg-Rüdinger M, Ullrich KK, Rensing SA (2017) Sexual reproduction, sporophyte development and molecular variation in the model moss Physcomitrella patens: introducing the ecotype Reute. Plant J 90:606-620. https://doi.org/10.1111/tpj.13501
Ho J, Adeolu M, Khadka B, Gupta RS (2016) Identification of distinctive molecular traits that are characteristic of the phylum "Deinococcus-Thermus" and distinguish its main constituent groups. Syst Appl Microbiol 39:453-463. https://doi.org/10.1016/j.syapm. 2016.07.003

Hohe A, Rensing SA, Mildner M, Lang D, Reski R (2002) Day length and temperature strongly influence sexual reproduction and expression of a novel MADS-box gene in the moss Physcomitrella patens. Plant Biol 4:595-602. https://doi.org/10. 1055/s-2002-35440

Huang C-K, Shen Y-L, Huang L-F, Wu S-J, Yeh C-H, Lu C-A (2016) The DEAD-Box RNA Helicase AtRH7/PRH75 participates in pre-rRNA processing, plant development and cold tolerance in Arabidopsis. Plant Cell Physiol 57:174-191. https://doi.org/10. 1093/pcp/pcv188

Hutchins AP, Roberts GR, Lloyd CW, Doonan JH (2004) In vivo interaction between CDKA and eIF4A: a possible mechanism linking translation and cell proliferation. FEBS Lett 556:91-94. https:// doi.org/10.1016/S0014-5793(03)01382-6

Katoh K, Standley DM (2013) MAFFT multiple sequence alignment software version 7: improvements in performance and usability. Mol Biol Evol 30:772-780. https://doi.org/10.1093/molbev/ mst010

Khraiwesh B, Qudeimat E, Thimma M, Chaiboonchoe A, Jijakli K, Alzahmi A, Arnoux M, Salehi-Ashtiani K (2015) Genome-wide expression analysis offers new insights into the origin and evolution of Physcomitrella patens stress response. Sci Rep 5:17434. https://doi.org/10.1038/srep17434

Kim M-H, Sonoda Y, Sasaki K, Kaminaka H, Imai R (2013) Interactome analysis reveals versatile functions of Arabidopsis COLD SHOCK DOMAIN PROTEIN 3 in RNA processing within the nucleus and cytoplasm. Cell Stress Chaperones 18:517-525. https://doi.org/10.1007/s12192-012-0398-3

Liang Z, Geng Y, Ji C, Du H, Wong CE, Zhang Q, Zhang Y, Zhang PP, Riaz A, Chachar S, Ding Y, Wen J, Wu YY, Wang M, Zheng H, Wu YY, Demko V, Shen L, Han X, Zhang PP, Gu X, Yu H (2020) Mesostigma viride genome and transcriptome provide insights into the origin and evolution of Streptophyta. Adv Sci. https://doi. org/10.1002/advs.201901850

Linder P, Owttrim GW (2009) Plant RNA helicases: linking aberrant and silencing RNA. Trends Plant Sci 14:344-352. https://doi.org/ 10.1016/j.tplants.2009.03.007

Liu Y, Tabata D, Imai R (2016) A cold-inducible DEAD-box RNA helicase from Arabidopsis thaliana regulates plant growth and development under low temperature. PLoS ONE. https://doi.org/ 10.1371/journal.pone. 0154040

Lorković ZJ, Herrmann RG, Oelmüller R (1997) PRH75, a new nucleus-localized member of the DEAD-box protein family from higher plants. Mol Cell Biol 17:2257-2265. https://doi.org/10. 1128/mcb.17.4.2257

Lu C-A, Huang C-K, Huang W-S, Huang T-S, Liu H-Y, Chen Y-F (2020) DEAD-Box RNA Helicase 42 plays a critical role in premRNA splicing under cold stress. Plant Physiol 182:255-271. https://doi.org/10.1104/pp.19.00832

Maxwell K, Johnson GN (2000) Chlorophyll fluorescence-a practical guide. J Exp Bot 51:659-668. https://doi.org/10.1093/jexbot/ 51.345 .659

Mdodana NT, Jewell JF, Phiri EE, Smith ML, Oberlander K, Mahmoodi S, Kossmann J, Lloyd JR (2019) Mutations in glucan, water dikinase affect starch degradation and gametophore development in the moss Physcomitrella patens. Sci Rep 9:15114. https://doi.org/10.1038/s41598-019-51632-9

Medina R, Johnson MG, Liu Y, Wickett NJ, Shaw AJ, Goffinet B (2019) Phylogenomic delineation of Physcomitrium (Bryophyta: Funariaceae) based on targeted sequencing of nuclear exons and their flanking regions rejects the retention of Physcomitrella, 
Physcomitridium and Aphanorrhegma. J Syst Evol 57:404-417. https://doi.org/10.1111/jse.12516

Meyberg R, Perroud P-F, Haas FB, Schneider L, Heimerl T, Renzaglia KS, Rensing SA (2020) Characterisation of evolutionarily conserved key players affecting eukaryotic flagellar motility and fertility using a moss model. New Phytol 227:440-454. https:// doi.org/10.1111/nph.16486

Nayak NR, Putnam AA, Addepalli B, Lowenson JD, Chen T, Jankowsky E, Perry SE, Dinkins RD, Limbach PA, Clarke SG, Downie AB (2013) An Arabidopsis ATP-Dependent, DEAD-Box RNA helicase loses activity upon isoAsp formation but Is restored by PROTEIN ISOASPARTYL METHYLTRANSFERASE. Plant Cell 25:2573-2586. https://doi.org/10.1105/tpc.113.113456

Ohnishi S, Pääkkönen K, Koshiba S, Tochio N, Sato M, Kobayashi N, Harada T, Watanabe S, Muto Y, Güntert P, Tanaka A, Kigawa T, Yokoyama S (2009) Solution structure of the GUCT domain from human RNA helicase II/Gu $\beta$ reveals the RRM fold, but implausible RNA interactions. Proteins Struct Funct Bioinforma 74:133-144. https://doi.org/10.1002/prot.22138

Ortiz-Ramírez C, Hernandez-Coronado M, Thamm A, Catarino B, Wang M, Dolan L, Feijó JA, Becker JD (2016) A transcriptome atlas of Physcomitrella patens provides insights into the evolution and development of land plants. Mol Plant 9:205-220. https://doi. org/10.1016/j.molp.2015.12.002

Ou Y, Fritzler MJ, Valdez BC, Rattner JB (1999) Mapping and characterization of the functional domains of the nucleolar protein RNA Helicase II/Gu. Exp Cell Res 247:389-398. https://doi.org/ 10.1006/excr.1998.4365

Pandey S, Muthamilarasan M, Sharma N, Chaudhry V, Dulani P, Shweta S, Jha S, Mathur S, Prasad M (2019) Characterization of DEAD-box family of RNA helicases in tomato provides insights into their roles in biotic and abiotic stresses. Environ Exp Bot 158:107-116. https://doi.org/10.1016/j.envexpbot.2018.11.018

Peltier J-BB, Yang C, Qi S, Zabrouskov V, Giacomelli LL, Rudella A, Ytterberg AJ, Rutschow H, van Wijk KJ, Cai Y, Sun Q, Zabrouskov V, Giacomelli LL, Rudella A, Ytterberg AJ, Rutschow H, van Wijk KJ (2006) The oligomeric stromal proteome of Arabidopsis thaliana chloroplasts. Mol Cell Proteomics 5:114-133. https://doi.org/10.1074/mcp.M500180-MCP200

Perroud PF, Quatrano RS (2006) The role of ARPC4 in tip growth and alignment of the polar axis in filaments of of Physcomitrella patens. Cell Motil cytoskelet 63(3):162-171

Perroud P-F, Cove DJ, Quatrano RS, Mcdaniel SF (2011) An experimental method to facilitate the identification of hybrid sporophytes in the moss Physcomitrella patens using fluorescent tagged lines. New Phytol 191:301-306. https://doi.org/10.1111/j.14698137.2011.03668.x

Perroud P-F, Meyberg R, Rensing SA (2019) Physcomitrella patens Reute mCherry as a tool for efficient crossing within and between ecotypes. Plant Biol 21:143-149. https://doi.org/10.1111/plb. 12840

Perroud P-F, Meyberg R, Demko V, Quatrano RS, Olsen OA, Rensing SA (2020) DEK1 displays a strong subcellular polarity during Physcomitrella patens 3D growth. New Phytol 226:1029-1041. https://doi.org/10.1111/nph.16417

Pfaffl MW (2001) A new mathematical model for relative quantification in real-time RT-PCR. Nucleic Acids Res 29:e45. https://doi.org/ 10.1093/nar/29.9.e45

Putnam AA, Jankowsky E (2013) DEAD-box helicases as integrators of RNA, nucleotide and protein binding. Biochim Biophys Acta 1829:884-893. https://doi.org/10.1016/j.bbagrm.2013.02.002

Rasband W (2018) ImageJ 1997-2018. U.S. National Institutes of Health, Bethesda

Reynolds ES (1963) The use of lead citrate at high $\mathrm{pH}$ as an electronopaque stain in electron microscopy. J Cell Biol 17:208-212. https://doi.org/10.1083/jcb.17.1.208
Rogers GWJ, Richter NJ, Merrick WC (1999) Biochemical and kinetic characterization of the RNA helicase activity of eukaryotic initiation factor 4A. J Biol Chem 274:12236-12244. https://doi.org/10. $1074 /$ jbc. 274.18 .12236

Rosado A, Li R, van de Ven W, Hsu E, Raikhel NV (2012) Arabidopsis ribosomal proteins control developmental programs through translational regulation of auxin response factors. Proc Natl Acad Sci U S A 109:19537-19544. https://doi.org/10.1073/pnas.1214774109

Ruijter JM, Ramakers C, Hoogaars WMH, Karlen Y, Bakker O, van den Hoff MJB, Moorman AFM (2009) Amplification efficiency: linking baseline and bias in the analysis of quantitative PCR data. Nucleic Acids Res 37:e45-e45. https://doi.org/10.1093/ nar/gkp045

Schaefer DG, Zrÿd J-P (1997) Efficient gene targeting in the moss Physcomitrella patens. Plant J 11:1195-1206. https://doi.org/10. 1046/j.1365-313X.1997.11061195.x

Schaefer DG, Delacote F, Charlot F, Vrielynck N, Guyon-Debast A, Le Guin S, Neuhaus J-M, Doutriaux MP, Nogué F (2010) RAD51 loss of function abolishes gene targeting and de-represses illegitimate integration in the moss Physcomitrella patens. DNA Repair (Amst) 9:526-533. https://doi.org/10.1016/j.dnarep.2010.02.001

Singleton MR, Dillingham MS, Wigley DB (2007) Structure and mechanism of helicases and nucleic acid translocases. Annu Rev Biochem 76:23-50. https://doi.org/10.1146/annurev.biochem.76. 052305.115300

Spurr AR (1969) A low-viscosity epoxy resin embedding medium for electron microscopy. J Ultrastruct Res 26:31-43. https://doi.org/ 10.1016/s0022-5320(69)90033-1

Staub E, Fiziev P, Rosenthal A, Hinzmann B (2004) Insights into the evolution of the nucleolus by an analysis of its protein domain repertoire. BioEssays 26:567-581. https://doi.org/10.1002/bies. 20032

Tanner NKK, Linder P (2001) DExD/H Box RNA Helicases: from generic motors to specific dissociation functions. Mol Cell 8:251262. https://doi.org/10.1016/S1097-2765(01)00329-X

Thelander M, Landberg K, Sundberg E (2018) Auxin-mediated developmental control in the moss Physcomitrella patens. J. Exp, Bot

Trouiller B, Schaefer DG, Charlot F, Nogué F (2006) MSH2 is essential for the preservation of genome integrity and prevents homeologous recombination in the moss Physcomitrella patens. Nucleic Acids Res 34:232-242

Tyagi V, Parihar V, Malik G, Kalra V, Kapoor S, Kapoor M (2020) The DEAD-box RNA helicase eIF4A regulates plant development and interacts with the hnRNP LIF2L1 in Physcomitrella patens. Mol Genet Genomics 295:373-389. https://doi.org/10. 1007/s00438-019-01628-x

Valdez BC (2000) Structural domains involved in the RNA folding activity of RNA helicase II/Gu protein. Eur J Biochem 267:63956402. https://doi.org/10.1046/j.1432-1327.2000.01727.x

Valdez BC, Henning D, Perlaky L, Busch RK, Busch H (1997) Cloning and characterization of $\mathrm{Gu} / \mathrm{RH}-\mathrm{II}$ binding protein. Biochem Biophys Res Commun 234:335-340. https://doi.org/10.1006/bbrc. 1997.6642

Vitha S, Baluška F, Volkmann D, Barlow P (2000) Steedman's wax for F-actin visualization. In: Baluška F, Barlow PW, Staiger CJ, Volkmann D (eds) Actin: a dynamic framework for multiple plant cell functions. Kluwer, Dordrecht, pp 619-636

Wang D, Qin B, Li X, Tang D, Zhang Y, Cheng Z, Xue Y (2016) Nucleolar DEAD-Box RNA Helicase TOGR1 regulates thermotolerant growth as a pre-rRNA chaperone in rice. PLOS Genet 12:e1005844

Xiao L, Wang H, Wan P, Kuang T, He Y (2011) Genome-wide transcriptome analysis of gametophyte development in Physcomitrella patens. BMC Plant Biol 11:177. https://doi.org/10.1186/ 1471-2229-11-177 
Xu R, Zhang S, Huang J, Zheng C (2013) Genome-wide comparative in silico analysis of the RNA helicase gene family in Zea mays and Glycine max: A comparison with Arabidopsis and Oryza sativa. PLoS ONE. https://doi.org/10.1371/journal.pone.0078982
Publisher's Note Springer Nature remains neutral with regard to jurisdictional claims in published maps and institutional affiliations. 